\title{
Evolution of subglacial overdeepenings in response to sediment redistribution and glaciohydraulic supercooling
}

\author{
Timothy T. Creyts, ${ }^{1}$ Garry K. C. Clarke, ${ }^{2}$ and Michael Church $^{3}$ \\ Received 16 August 2012; revised 18 December 2012; accepted 15 January 2013.
}

[1] Glaciers erode bedrock rapidly, but evacuation of sediments requires efficient subglacial drainage networks. If glaciers erode more rapidly than evacuation proceeds, a protective subglacial till layer can form to armor the bed. Where glaciers cross overdeepenings, local closed depressions, the bed slope opposes the ice surface and lowers the hydraulic potential gradient that drives water flow. Here, we present results of a dynamic, distributed model of coupled basal water flow and sediment transport to show how overdeepenings evolve over the course of a melt season. We use steady-state calculations as well as numerical simulations to understand how alluvial bed erosion alters overdeepenings. Numerical results from a modified form of the Spring-Hutter equations show behaviors that cannot be inferred from either local or steady-state calculations. In general, opposition of surface and bed slopes lessens sediment transport regardless of ice accretion from glaciohydraulic supercooling. Drainage efficiency strongly affects erosion and deposition rates. Results show characteristic behaviors of flow through overdeepenings such as overpressured water systems and accretion rates compatible with field measurements. Simulations that start with overdeepened glacier configurations progress out of a freezing regime where glaciohydraulic supercooling occurs. This progression indicates that glacier hydrology is more strongly affected by erosion and deposition than by freezing from glaciohydraulic supercooling. We discuss how this outcome affects glacier erosion and sediment transport under modern and past ice sheets.

Citation: Creyts, T. T., G. K. C. Clarke, and M. Church (2013), Evolution of subglacial overdeepenings in response to sediment redistribution and glaciohydraulic supercooling, J. Geophys. Res. Earth Surf., 118, doi:10.1002/jgrf.20033.

\section{Introduction}

[2] Erosion of mountain ranges can proceed rapidly where glaciers occupy valleys [e.g., Hallet et al., 1996]. A variety of glacial erosion mechanisms operate, many in concert, along the valley walls above the glacier as well as along the walls and floor below the ice surface. Mechanical processes, such as quarrying [Hallet, 1996] and abrasion [Hallet, 1979], erode the subglacial bed. If evacuation rates of sediments along the base of a glacier do not keep pace with erosion, then sediments remain along the ice-bed interface and a protective till cover develops over the bedrock [Alley et al., 2003a; Hooke, 1991]. Erosion of subglacial

\footnotetext{
All supporting information may be found in the online version of this article.

${ }^{1}$ Lamont-Doherty Earth Observatory, Columbia University, Palisades, New York, USA.

${ }^{2}$ Department of Earth and Ocean Sciences, University of British Columbia, Vancouver, British Columbia, Canada.

${ }^{3}$ Department of Geography, University of British Columbia, Vancouver, British Columbia, Canada.

Corresponding author: T. T. Creyts, Lamont-Doherty Earth Observatory, Columbia University, 61 Rt. 9W, Palisades, NY 10964, USA. (tcreyts@1deo.columbia.edu)

(C)2013. American Geophysical Union. All Rights Reserved. 2169-9003/13/10.1002/jgrf.20033
}

bedrock only restarts when sediments have been evacuated. Conversely, where evacuation is relatively fast, bedrock will be exposed to overlying ice, and erosion can proceed.

[3] Subglacial sediments can be evacuated through ice motion or transport in subglacial water. For ice flow to be effective, shear must be transferred to the underlying sediments to cause till advection [Tulaczyk et al., 2001]. Alternatively, sediments could be accreted to the base of the glacier. Movement of the freezing front into the bed can accrete large volumes of sediment [e.g., Rempel, 2008]. Other mechanisms include downward ice intrusion by regelation [Iverson and Semmens, 1995] and freeze-on by regelation around obstacles [Weertman, 1957]. Both types of regelation processes were successfully incorporated into a model of North American ice sheets to advect sediment [Hildes et al., 2004]. Additionally, freeze-on through glaciohydraulic supercooling, lowering of the pressure melting point faster than the water warms via viscous dissipation, can accrete large volumes of sediment [e.g., Cook and Swift, 2012; Cook et al., 2007, Lawson et al., 1998]. Observations of glaciohydraulic supercooling tend to focus near glacier termini, but subglacial water can flow through multiple overdeepenings, with accretion of basal ice and sediment along each adverse slope. Accreted ice could subsequently melt where ice flows down into the next overdeepening. Exposed ice at the front of a glacier likely records a complex history of changing basal conditions. 
[4] Basal water systems can evacuate sediment rapidly [Hallet et al., 1996]. Beneath alpine glaciers, basal water systems develop seasonally with surface melt and subsequent meltwater input, transforming an inefficient, distributed system with low hydraulic gradients to a transmissive, concentrated basal water system that has steep hydraulic gradients [e.g., Iken and Bindschadler, 1986; Nienow et al., 1998; Schoof, 2010]. Efficiency implies that water moves quickly through the system at low pressures with passages that are large enough to move sediment. A transmissive basal water system implies that the combination of water depth and hydraulic conductivity is relatively large, making a deep and connected water system. Because development, duration, and spatial extent of a subglacial drainage system depend on meltwater supply, high evacuation rates often correlate to high surface melt rates.

[5] Evacuation relies on relatively steep hydraulic gradients driving flow. To switch from evacuation to deposition of sediments, basal water must flow from an area of efficient drainage to one of inefficient drainage. Deposition of sediments occurs where transmissivity declines, either through flatter hydraulic gradients or shallower water depths. Both changes often occur simultaneously because there is a relation between hydraulic gradient and water depth for a connected basal water system [Creyts and Schoof, 2009; Nye, 1976; Schoof, 2010]. However, if hydraulic gradients steepen along with water velocities that are high enough to transport sediment, then the subglacial water system can continue to evacuate sediment or strip the bed of sediment to expose bedrock.

[6] The switch from efficient to inefficient drainage results from a multitude of processes, and many of these depend on the hydraulic potential. If the bed rises and becomes adverse to flow, the hydraulic gradient is lowered. If the bed is sufficiently steep, then glaciohydraulic supercooling permits ice to form because the water cannot warm as fast as it changes its pressure melting point. Alley et al. [2003a] developed this hypothesis as the basis of a stabilizing feedback in glacier-bed erosion: glaciers that erode their bed too efficiently will form overdeepenings that in turn trap sediment and reduce erosion locally. Formation of ice in a drainage system constricts flow, increases upstream subglacial water pressure, and can cause divergence of water into laterally contiguous areas along the ice-bed interface. If divergence of water is coincident with a reduction in the hydraulic gradient and if water is carrying sediment, then deposition will occur. Furthermore, they reasoned that the adverse slope evolves to the critical threshold necessary for glaciohydraulic supercooling.

[7] If surface and bed slopes are driven to this critical threshold, there could be a thermodynamic feedback to glaciofluvial sediment transport that traps sediment, shields subglacial bedrock from erosion, and limits the depth of glacial erosion. Trapping of sediment modifies the hydraulic gradient driving water flow by changing the ratio of the surface to bed slopes. If glacier bed and surface configurations are driven to the threshold slope ratio, then there would be implications for large-scale development of glacial valley networks and mountain belt evolution [Alley et al., 2003a].

[8] Here, we investigate the relations among overdeepenings, glaciohydraulic supercooling, and subglacial sediment transport to understand how glaciers can create an armored bed to limit glacier erosion. We use a quantitative model to draw out diagnostic behaviors. Our strategy employs a continuum theory developed for subglacial water flow [Clarke, 2003; Spring and Hutter, 1981, 1982] expanded for subglacial sediment transport. Creyts and Clarke [2010] used an equivalent formulation for supercooling in clear water flows, and we expand upon their work for an alluvial, erodible bed with sediment transport. We assume a priori that an overdeepening exists and infer its development based on erosion and deposition and erosion of sediment along the bed. In what follows, we review relevant observations, explain conditions necessary for sediment transport and freezing of subglacial water, and show how our model is constructed.

\subsection{Background}

[9] Overdeepenings are a characteristic feature of glacial landscapes [Sugden and John, 1976], and upon glacier retreat, these depressions are commonly occupied by glacial lakes [Benn and Evans, 1998, chapter 12]. Overdeepenings are closed depressions in bed topography beneath a glacier with lateral dimensions comparable to or greater than the overlying ice thickness [for a comprehensive review, see Cook and Swift, 2012]. At their downstream end, a slope opposing ice flow, commonly called an adverse slope, rises from the depression. Overdeepenings can be found at all elevations in a glacial landscape, from glacial cirques [Hooke, 1991] to large depressions along valley floors.

[10] Glaciohydraulic supercooling occurs in water networks beneath temperate glaciers as water ascends an adverse slope such that heat produced from viscous dissipation is insufficient to raise the water temperature above the pressure melting point [Alley et al., 1998; Creyts and Clarke, 2010; Röthlisberger and Lang, 1987]. Any sensible heat is used and latent heat is released as water rises, to form ice in the flowing water. Observations show that glaciohydraulic supercooling can accrete meter-thick sections of basal ice depending on conditions such as subglacial water discharge and bed slope steepness [Cook et al., 2007; Lawson et al., 1998; Strasser et al., 1996].

[11] If water is sufficiently turbid, sediment can accrete where glaciohydraulic supercooling occurs (Figure 1). Sediment content in accreted basal ice at Matanuska Glacier typically ranges from $15 \%$ to $60 \%$ by volume but can be practically none to almost entirely sediment [Lawson et al., 1998]. Fine sediment (silt and sand) dominates stratified layers with fewer coarse-grained layers [Lawson, 1979]. Lawson et al. [1998] showed that silt-dominated layers resemble features that have formed as frazil ice flocs entrain sediment. Frazil ice, which forms platy, discoid crystals, indicates supercooling [e.g., Carstens, 1966; Daly, 1984], and high concentrations of sediment in lower, stratified facies indicate turbulent subglacial water flow [Lawson et al., 1998].

[12] Basal ice layers are commonly separated into facies based on crystal textures, air bubbles, sediment content, and relations to other layers [e.g., Cook et al., 2007; Hubbard et al., 2009; Lawson et al., 1998; Lawson, 1979]. The stratified facies at Matanuska Glacier is the thickest of the observed accreted basal facies and appears to have the strongest connection to glaciohydraulic supercooling with 0.02-74\% debris content [Lawson, 1979; Lawson et al., 1998]. At Svínafellsjökull and Skaftafellsjökull, Iceland, basal facies consistent with supercooling have mean debris 


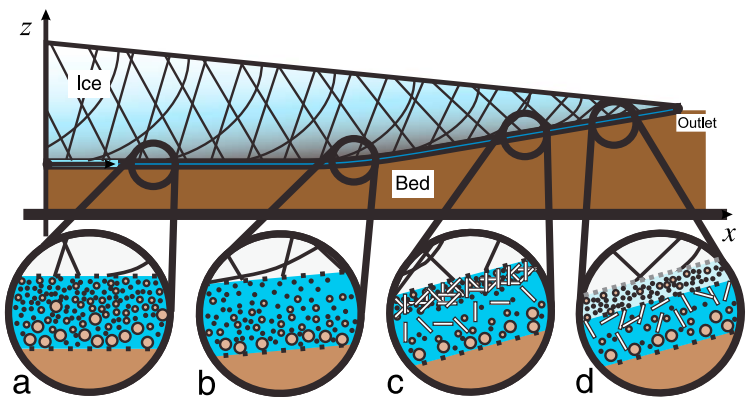

Figure 1. Illustration of sediment transport at the ice-bed interface through overdeepenings as discussed by previous authors [Alley et al., 2003a; Alley et al., 1998; Hooke, 1991; Hooke and Pohjola, 1994; Lawson et al., 1998). Thin dark lines represent an englacial fracture network. (a) Sediment-laden water flows into an overdeepening. (b) When water begins to flow up the overdeepening, the gradient driving flow is reduced. As water velocity slows, sediment is deposited. (c) Frazil ice (illustrated as white rectangles) begins to form. Sediment filters through the frazil flocs. Water pathways must be kept open by water pressures in excess of ice overburden instead of by melt from by viscous dissipation [Röthlisberger, 1972]. High pressures allow water to diverge along the bed. (d) Sediment is trapped as the pore water in frazil flocs freezes to accrete basal ice.

contents in the range $21-83 \%$ by volume [Cook et al., 2010]. These facies are strongly dominated by silt and fine sand with gravel contents in the range $0-17 \%$. Other work at Skeiarárjökull and Skaftafellsjökull demonstrates the occurrence of glaciohydraulic supercooling and shows much sediment transport and accretion [Roberts et al., 2002]. Radio echo soundings from Muir Glacier, Alaska, reveal a terminal overdeepening with debris-rich basal ice [Alley et al., 2003b].

[13] Sediment concentrations in water discharged from overdeepenings are high but within the range of other glaciated areas. Suspended sediment concentrations at Matanuska Glacier range from 0.3 to $5 \mathrm{~g} \mathrm{~L}^{-1}$ and vary with diurnal and seasonal changes [Lawson et al., 1998]. Time series of sediment discharge show excursions to about $20 \mathrm{~g} \mathrm{~L}^{-1}$ at Matanuska Glacier [Pearce et al., 2003]. Bed load fluxes that emerge from the margin are in the range $0-10 \mathrm{~g} \mathrm{~m}^{-1} \mathrm{~s}^{-1}$ (mass flux per unit channel width) and are commonly dominated by sand (grain diameters of $0.25-2 \mathrm{~mm}$ ) and granules (grain diameters of 2-4 mm ) [Pearce et al., 2003]. For comparison, other glaciers have similar sediment discharge even though there is no observed supercooling. For example, measurements from Haut Glacier d'Arolla, Switzerland and Midtdalsbreen, Norway, show summertime suspended loads near the range of Matanuska Glacier [Richards et al., 1996; Willis et al., 1996]. Alaskan proglacial rivers, for comparison, can have sediment concentrations as high as $3 \mathrm{~g} \mathrm{~L}^{-1}$ but commonly have maximum sediment concentrations of $1.5 \mathrm{~g} \mathrm{~L}^{-1}$ [Lawson, 1993].

\subsection{Scope}

[14] Subglacial hydraulic systems depend on three main variables: gradient driving flow, the subglacial effective pressure (usually defined as ice overburden pressure minus water pressure), and the water depth along the basal interface. These three quantities are intimately linked, and a change in one can result in a change in the other two [Nye, 1976; Creyts and Schoof, 2009; Creyts and Clarke, 2010; Schoof, 2010]. For example, erosion of loose bed sediments depends on the gradient driving water flow. Where sediment erodes, water depth increases. The effective pressure then changes if erosion is not constant along flow. Melt and accretion of ice also change water depth, and where a change in water depth is not offset by a mass flux, the effective pressure must change.

[15] Different manifestations of the linkages among these variables exist for glaciers. At Storglaciären, water pressures exceed ice overburden at the base of the overdeepening where bed slopes are steepest [Hooke and Pohjola, 1994]. Similarly, effluent summertime discharge at Matanuska Glacier is commonly artesian [Lawson et al., 1998]. Hydraulic gradients along the terminal overdeepening are low [Creyts and Clarke, 2010; Lawson et al., 1998], but sediment transport out of the overdeepening can be very high [Lawson et al., 1998; Pearce et al., 2003]. Other glaciers show signs of overpressurization of the hydraulic system with variable amounts of sediment flux through the basal water system [e.g., Roberts et al., 2002; Tweed et al., 2005]. Arguments have been posed that water flow is not along the bed but traverses overdeepenings through englacial pathways [Fountain et al., 2005; Hooke, 1991; Hooke and Pohjola, 1994]. However, there are many observations where subglacial water flow must be the dominant mechanism of drainage so we do not consider englacial flow further.

[16] To simplify drainage structure, we consider a onedimensional flow path along the base of a glacier where sediment can be eroded and accreted to the base of the glacier. We assume a priori that the overdeepening exists and consider its development as water and sediment move through the basal system. The numerical model allows us to look at along-path variations in water fluxes, accretion magnitudes, and sediment transport rates. Additionally, the model allows us to investigate the locations of sediment deposition and accretion and relate this to melt and accretion along the flow path. Results from the numerical model can be used to examine whether there is an optimal location for accretion along an overdeepened slope and the relation between the concentrations of sediment in the flowing water and accreted ice. Following Creyts and Clarke [2010], we use both constant forcing and diurnal forcing as bounds on behaviors to make qualified statements on the evolution of overdeepenings and the redistribution of sediment via both water and ice-bound transport.

\section{Model}

[17] We consider an ice-bed interface where flowing water overlies a floor of loose, erodible sediments that is confined by a ceiling of overlying ice. Because observations of accreted ice layers show them to be much broader than high, we expect water flow to be distributed and consider vertically integrated flow in a water sheet. Water progresses along a one-dimensional flow path and ascends a slope adverse to flow. Large protrusions penetrate the water sheet and partially support the weight of the overlying ice [e.g., Creyts and Clarke, 2010; Creyts and Schoof, 2009].

[18] Sediment transport is fully coupled to water flow. Erosion or deposition of sediment instantaneously affects water depth. In order to obtain this coupling, we employ reasonably scaled arguments from the subaerial fluvial literature. Potential 
gradients that drive water flow are within the range of natural rivers, and both subaerial and subglacial sediment transport is dilute relative to the amount of water discharge.

[19] Because the melting point of water is pressure dependent, glaciohydraulic supercooling occurs where water flows up an adverse slope at a rate faster than heat can be added to keep the water at the pressure melting point [Alley et al., 1998; Creyts and Clarke, 2010; Röthlisberger and Lang, 1987]. Glaciohydraulic supercooling leads to ice formation, and latent heat released from ice formation warms the remaining water. Following Creyts and Clarke [2010], we incorporate these thermodynamic effects.

\subsection{Flow Equations}

[20] We use a form of the Spring-Hutter equations [Clarke, 2003; Spring and Hutter, 1981, 1982] to investigate subglacial water flow originally derived for drainage of subglacial flood waters through tubular conduits. These equations were extended successfully to clear water flow in subglacial sheets [Creyts and Clarke, 2010].

[21] Relative to equivalent clear water flows, the balance laws for sediment transport are more detailed because there are three phases: water, ice, and sediment. However, all equations reduce to their clear water counterparts when terms representing sediment supply ( $\widetilde{\Psi}$ 's) and sediment concentration ( $\lambda$ 's) are set to zero. Our mathematical description contains a level of complexity that captures the necessary features of subglacial sediment transport and thermodynamics.

[22] Water flowing in a distributed sheet across the bed has a width $W$ that is much greater than its depth $H,(W \gg H)$. The water path at the ice-bed interface follows coordinate $s$ where an increment is defined as $d s=\sqrt{d x^{2}+d z^{2}}$ with $x$ the regular longitudinal coordinate and $z$ the vertical coordinate (Figure $2 a$ ). Glacier ice overlies a basal water system with a loose sediment bed underneath.

[23] Subglacial water flows down the gradient of hydraulic potential $\phi$,

$$
\frac{\partial \phi}{\partial s}=\rho_{\mathrm{w}} g \frac{\partial z_{\mathrm{w}}}{\partial s}+\frac{\partial p_{\mathrm{w}}}{\partial s}
$$

where $p_{\mathrm{w}}$ is water pressure, $\rho_{\mathrm{w}}$ is water mass density, $g$ is gravitational acceleration, and $z_{\mathrm{w}}$ is the elevation of the subglacial ice-water interface. We can also rewrite equation (1a) to include effective pressure $p_{e}$,

$$
\begin{gathered}
p_{e}=p_{\mathrm{i}}-p_{\mathrm{w}}, \\
\frac{\partial \phi}{\partial s}=\rho_{\mathrm{w}} g \frac{\partial z_{\mathrm{w}}}{\partial s}+\frac{\partial p_{\mathrm{i}}}{\partial s}-\frac{\partial p_{e}}{\partial s} .
\end{gathered}
$$

[24] Collectively, $\rho_{\mathrm{w}} g z_{\mathrm{w}}$ is the gravitational potential and contains information about bed slope. Provided that the pressure gradient is greater than the gravitational potential gradient $\left(\partial p_{\mathrm{w}} / \partial s>\rho_{\mathrm{w}} g \partial z_{\mathrm{w}} / \partial s\right)$, water can flow out of a subglacial overdeepening while flowing down the potential gradient [Shreve, 1972]. Similarly, from equation (1c), if the effective pressure gradient increases along flow such that water runs from an area of high pressure to low, and this gradient exceeds the gravitational potential gradient, then water can flow out of an overdeepening.

[25] Written as state evolution equations for subglacial water flow, the vertically integrated, local balance equations reduce to the rate of change of water depth $H$, water pressure $p_{\mathrm{w}}$, along-path water velocity $u$, and water temperature $T_{\mathrm{w}}$,

a

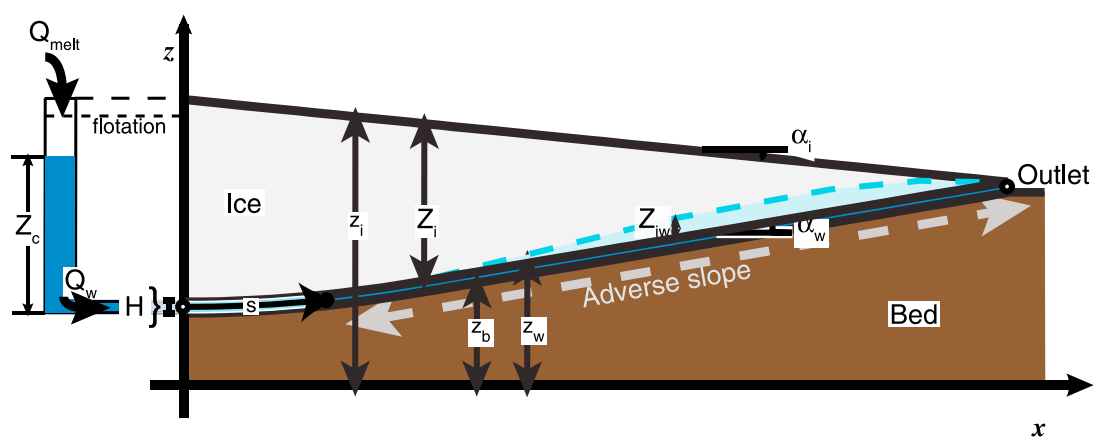

b

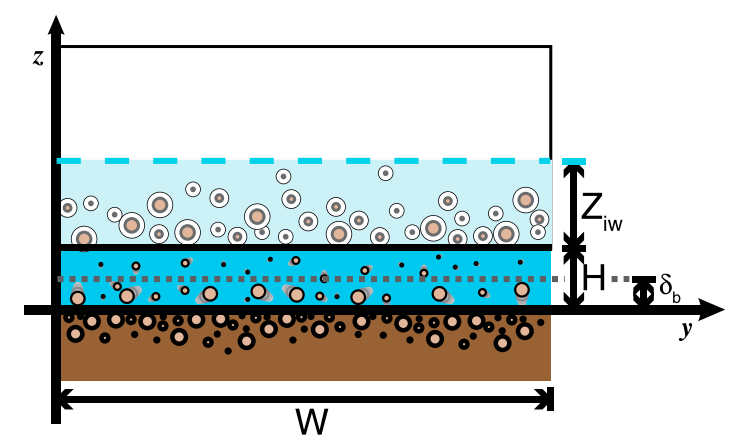

Figure 2. Geometry of the overdeepening. (a) Longitudinal section showing relevant variables defined in the text. Upstream feeder crevasse is a surrogate for upstream hydrology. (b) Cross section of sheet flow with water flow out of the page. Sediment not only is transported in water but also is frozen in ice. Large grains travel in the bedload layer $\delta_{\text {bed }}$ (see the Supplementary Online Material). 


$$
\begin{aligned}
& \underbrace{\frac{\partial H}{\partial t}}_{\begin{array}{c}
\text { Water depth } \\
\text { evolution }
\end{array}}=\underbrace{\frac{1}{\left(1-n_{\mathrm{i}}\right) \rho_{\mathrm{i}}+n_{\mathrm{i}} \rho_{\mathrm{w}}}}_{\begin{array}{c}
\text { Mixture } \\
\text { coefficient }
\end{array}}\{\underbrace{\left[1+\frac{n_{\mathrm{i}} \rho_{\mathrm{w}}}{\left(1-\lambda_{\mathrm{si}}\right)\left(1-n_{\mathrm{i}}\right) \rho_{\mathrm{i}}}\right]}_{\text {Melt rate term }} \widetilde{m}+\underbrace{\left[1-\left(1-n_{\mathrm{i}}\right)\left(1-\frac{\rho_{\mathrm{i}}}{\rho_{\mathrm{s}}}\right)\right]}_{\text {Sediment supply from ice term }} \widetilde{\Psi}_{\mathrm{i}}\} \\
& +\underbrace{\frac{\widetilde{\Psi}_{\mathrm{b}}}{\left(1-n_{\mathrm{b}}\right) \rho_{\mathrm{s}}}}_{\text {Erosion and }}+\underbrace{\left(\frac{\partial H}{\partial t}\right)_{\text {close }}}_{\text {Closure rate from }}, \\
& \begin{array}{cc}
\begin{array}{c}
\text { Erosion and } \\
\text { sedimentation term }
\end{array} & \begin{array}{c}
\text { Closure rate from } \\
\text { ice intrusion }
\end{array}
\end{array}
\end{aligned}
$$

$\underbrace{\frac{\partial p_{\mathrm{w}}}{\partial t}}_{\begin{array}{c}\text { Water pressure } \\ \text { evolution }\end{array}}=-\frac{1}{\gamma H}(\underbrace{\frac{\partial H}{\partial t}+\frac{\partial(H u)}{\partial s}}_{\begin{array}{c}\text { Material derivative of } \\ \text { flowing water }\end{array}}-\frac{1}{\rho_{\mathrm{w}}}\{\underbrace{-H\left(\rho_{\mathrm{s}}-\rho_{\mathrm{w}}\right)\left[\frac{\partial \lambda_{\mathrm{sw}}}{\partial t}+u \frac{\partial \lambda_{\mathrm{sw}}}{\partial s}\right]}_{\begin{array}{c}\text { Term from the balance of } \\ \text { sediment in water }\end{array}}+\underbrace{\left[1+\frac{n_{\mathrm{i}} \rho_{\mathrm{w}}}{\left(1-\lambda_{\mathrm{si}}\right)\left(1-n_{\mathrm{i}}\right) \rho_{\mathrm{i}}}\right] \tilde{m}}_{\text {Melt rate term }}$

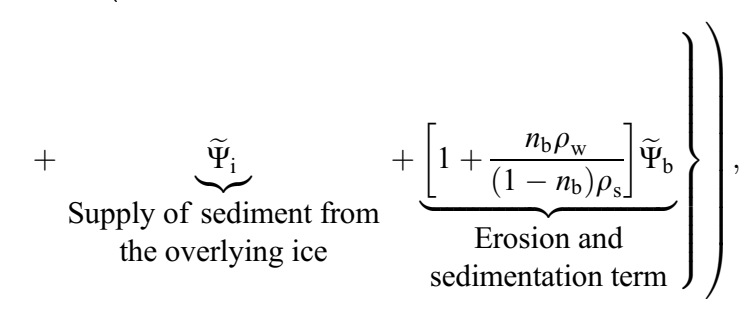

$$
\underbrace{\frac{\partial u}{\partial t}}=\underbrace{-u \frac{\partial u}{\partial s}}-\underbrace{\left\{\left[1+\frac{n_{\mathrm{i}} \rho_{\mathrm{w}}}{\left(1-\lambda_{\mathrm{si}}\right)\left(1-n_{\mathrm{i}}\right) \rho_{\mathrm{i}}}\right] \widetilde{m}+\widetilde{\Psi}_{\mathrm{i}}+\left[1+\frac{n_{\mathrm{b}} \rho_{\mathrm{w}}}{\left(1-n_{\mathrm{b}}\right) \rho_{\mathrm{s}}}\right] \widetilde{\Psi}_{\mathrm{b}}\right\} \frac{u}{\rho_{\mathrm{w}} H}}
$$

Water velocity Inertial term from evolution
Impulse terms from material moving off the sediment bed or ice ceiling surrounding the water

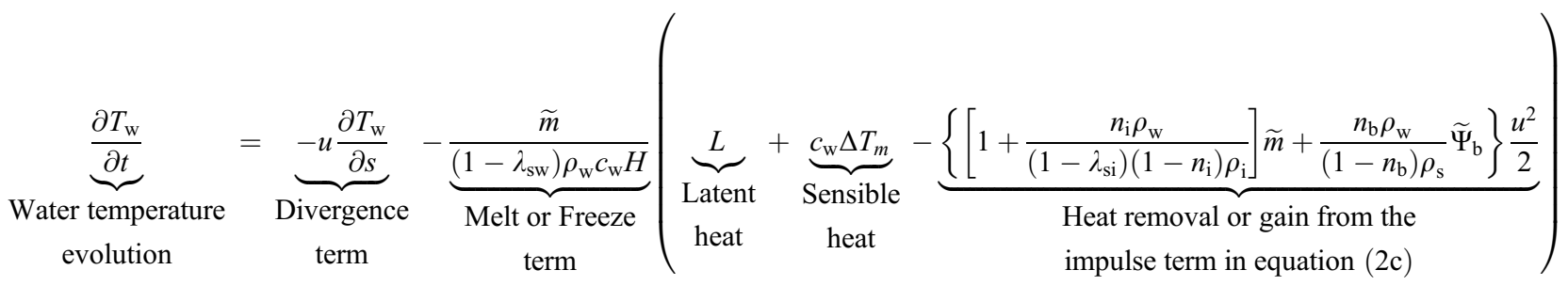

$$
\begin{aligned}
& +\underbrace{\frac{2}{H} \frac{\tau_{0} u}{\left(1-\lambda_{\mathrm{sw}}\right) \rho}}_{\text {Vicious heating }} .
\end{aligned}
$$


where $\rho_{\mathrm{i}}$ and $\rho_{\mathrm{s}}$ are the mass densities of ice and dry sediment, respectively. Average sediment concentrations (volume of sediment per unit volume) in the ice and water are $\lambda_{\mathrm{si}}$ and $\lambda_{\mathrm{sw}}$, respectively, and $n_{\mathrm{i}}$ and $n_{\mathrm{b}}$ are porosities of the ice and bed, respectively. Total volume is a combination of the individual mixture components such that coefficients that contain both concentrations or porosities will sum to unity.

[26] Mass can be supplied to the water from an ice roof via melt per unit width $\widetilde{m}$, or sediment supplied as the roof melts $\widetilde{\Psi}_{i}$. Erosion or deposition along the bed is represented by the supply term $\widetilde{\Psi}_{\mathrm{b}}$. Creyts and Clarke [2010] defined the melt rate as mass melt rate per unit length $m$ consistent with previous studies [Spring and Hutter, 1981, 1982; Clarke, 2003]. We keep this same notation for melt rate per unit flow width $\widetilde{m}:=m / W$ and apply the same notation for sediment supply from ice or bed as $\widetilde{\Psi}_{\mathrm{i}}:=\Psi_{\mathrm{i}} / W$ and $\widetilde{\Psi}_{\mathrm{b}}:=\Psi_{\mathrm{b}} / W$. Quantities with tildes always denote mass exchange rates between the flowing water and either the overlying ice roof or underlying subglacial bed. The sheet closure rate is $(\partial H / \partial t)_{\text {close }}$ where we create a lookup table of values from Creyts and Schoof [2009] in the same way as Creyts and Clarke [2010].

[27] Both equations (2a) and (2b) are derived from mass balances. Equation (2a) is derived from the mass balance along the hydraulic perimeter [Spring and Hutter, 1981; Walder and Fowler, 1994]. Water depth increases either through the melting of overlying ice or through the erosion of sediments, but can decrease when water freezes to the roof, sedimentation occurs, or the overlying ice closes the water system. When the bed is eroding, both sediment and pore water are supplied from the bed to the flow. The porosity of the bed determines the volume of water that enters the flow as the bed erodes. Supply of water is only from the arrangement of grains and pores, and we make no allowance for a possible supply of water from a basal aquifer. Equation (2b) comes from the mass balance of flowing water and incorporates a common compressibility transformation to create a state evolution for pressure [e.g., Clarke, 2003] where $\gamma$ is the compressibility of the subglacial water system.

[28] In the local water velocity equation $(2 c), \tau_{0}$ is shear along the hydraulic perimeter. We also expect $\lambda_{\mathrm{sw}} \ll 1$, so water density is an adequate approximation for the mixture of sediment and water that moves through the subglacial hydraulic system $\left(\rho_{\mathrm{w}} \simeq \lambda_{\mathrm{sw}} \rho_{\mathrm{s}}+\left(1-\lambda_{\mathrm{sw}}\right) \rho_{\mathrm{w}}\right)$. The impulse term in the curly braces is the momentum lost when sediment or ice is moved off the hydraulic boundary. Implicit in equation (2c) is that the concentration of sediment in the water $\lambda_{\text {sw }}$ does not significantly affect the water momentum.

[29] In the local water temperature equation (2d), $L$ is latent heat of ice, $c_{\mathrm{W}}$ is specific heat of water, and $\Delta \mathrm{T}_{m}=T_{\mathrm{w}}-T_{m}$ is the temperature of water relative to its freezing point. Mechanical work done in eroding and transporting sediment already appears in the momentum equation (2c), and no additional allowance is made in equation (2d) [Walder and Fowler, 1994]. We neglect the sensible heat of entrained sediment or subjacent pore water.

\subsection{Sediment, Erosion, Transport, and Freeze-on}

[30] For sediments to erode, water velocity must exceed a critical threshold. Where velocity falls below that threshold, the system relaxes to clear water conditions as discussed by Creyts and Clarke [2010]. We expect water to account for most of the mass transferred through the hydraulic system. Only a small mass fraction transported is sediment.

[31] We make the common distinction between bed load and suspended load where the former refers to larger grain sizes traveling in traction along the bed while the latter refers to smaller grain sizes that are readily supported in suspension by turbulent eddies [Henderson, 1966, chapter 10]. We track each of these parts of the sediment load. The transport formulas of van Rijn [1984a, 1984b] provide an appropriate scaling that is internally consistent for bed load and suspended load. We expect any given sediment transport rule to change the relative values of transport but not necessarily spatial or temporal trends. The suspended load formulas are specifically for suspended sand, but rather than introduce different rules for finer silt and clay transport, we assume that these behave as suspended sand. Some silt and clay flocculate together to behave as larger particles. Our main aim is to find appropriately scaled sediment transport rules.

[32] The total sediment concentration is the sum of the bed load concentration $\lambda_{\text {sw }}$ : bed and suspended load concentration $\lambda_{\text {sw : sus, }}$

$$
\lambda_{\mathrm{sw}}=\lambda_{\mathrm{sw}: \mathrm{bed}}+\lambda_{\mathrm{sw}: \mathrm{sus}}
$$

with $\lambda_{\text {sw: bed }}$ the bed load concentration and $\lambda_{\mathrm{sw} \text { : sus }}$ the suspended load concentration.

$$
\begin{aligned}
& \frac{\partial \lambda_{\text {sw:bed }}}{\partial t}=\frac{1}{\rho_{\mathrm{s}} H}(\underbrace{\widetilde{\Psi}_{\mathrm{b}: \text { bed }}}+\underbrace{\widetilde{\Psi}_{\text {si:bed }}}-\underbrace{\rho_{\mathrm{s}} \lambda_{\text {sw:bed }} \frac{\partial H}{\partial t}}-\rho_{\mathrm{s}} \underbrace{\frac{\partial q_{\mathrm{sw}} \text { bed }}{\partial s}}), \\
& \underbrace{\frac{\partial \lambda_{\text {sw:sus }}}{\partial t}}_{\begin{array}{c}
\text { Sediment } \\
\text { concentration } \\
\text { evolution }
\end{array}}=\frac{1}{\rho_{\mathrm{s}} H}(\underbrace{\widetilde{\Psi}_{\mathrm{b} \text { :sus }}}_{\begin{array}{c}
\text { Supply } \\
\text { from } \\
\text { the bed }
\end{array}}+\underbrace{\widetilde{\Psi}_{\text {si:sus }}}_{\begin{array}{c}
\text { Supply } \\
\text { from } \\
\text { the ice }
\end{array}}-\underbrace{\rho_{\mathrm{s}} \lambda_{\text {sw:sus }} \frac{\partial H}{\partial t}}_{\begin{array}{c}
\text { Change in } \\
\text { concentration from } \\
\text { a change in } \\
\text { water depth }
\end{array}}-\rho_{\mathrm{s}} \underbrace{\frac{\partial q_{\text {sw:sus }}}{\partial s}}_{\begin{array}{c}
\text { Divergence of } \\
\text { sediment flux }
\end{array}}),
\end{aligned}
$$


[33] From the mass balance of sediment in the water flow, the local rate of change of the sediment concentrations are, respectively,

where $\partial H / \partial t$ is given by equation (2a). Bed load flux $q_{\text {sw:bed }}$ and suspended sediment flux $q_{\text {sw:sus, }}$, are

$$
\begin{gathered}
q_{\text {sw:bed }}=u_{\text {bed }} \lambda_{\text {sw:bed }} \delta_{\text {bed }}, \\
q_{\text {sw:sus }}=u \lambda_{\text {sw:sus }} H
\end{gathered}
$$

where $u_{\text {bed }}$ is the bed load velocity, $\delta_{\text {bed }}$ is the bed load layer height (see Supplementary Online Material, section S3), and the total sediment flux is $q_{\mathrm{sw}}=q_{\mathrm{sw}}$ : bed $+q_{\mathrm{sw}}$ : bed. Sediment velocity is commonly correlated with water velocity using a semiempirical relation [e.g., Gomez and Church, 1989]. For bed load, velocity correlations are typically a function of the fluid velocity and shear stress along the bed [e.g., van Rijn, 1984a; Bagnold, 1973]. Suspended load, however, is commonly assumed to travel at the mean water velocity [e.g., Wu et al., 2004; van Rijn, 1984b].

\subsubsection{Erosion and Deposition}

[34] The bed elevation changes when either erosion or deposition occurs. The rate of change of the bed elevation $z_{\mathrm{b}}$, is

$$
\frac{\partial z_{\mathrm{b}}}{\partial t}=-\frac{1}{\left(1-n_{\mathrm{b}}\right) \rho_{\mathrm{s}}} \widetilde{\Psi}_{\mathrm{b}}
$$

where $n_{\mathrm{b}}$ is the porosity of the bed, and $\widetilde{\Psi}_{\mathrm{b}}$ is the total supply from the bed below of both suspended and bed load sediment. We assume that the bed does not move or deform, so that any advective velocity of the bed is neglected. Because equation (6) stems from the mass balance of the bed, we have assumed that the pore water and sediment matrix are incompressible, the sediment is water saturated, and the porosity is constant. Equation (6) is a form of the Exner equation [e.g., Henderson, 1966, chapter 10].

[35] The mass supply of sediments to a subglacial water system $\Psi_{\mathrm{b}}$, is the erosion or sedimentation rate depending on whether it is positive or negative, respectively. Following Einstein [1968], the instantaneous sediment load $q_{\mathrm{s}}$ is driven back to an equilibrium value $q_{\mathrm{sw}, \mathrm{e}}$ such that their difference over an adaptation length $L_{\mathrm{s}}$ determines supply of sediment from the bed

$$
\Psi_{\mathrm{b}}=\rho_{\mathrm{s}}\left(q_{\mathrm{sw}, \mathrm{e}}-q_{\mathrm{sw}}\right) / L_{\mathrm{s}} .
$$

[36] The equilibrium sediment flux can be determined from any of a number of semiempirical relations [e.g., Garcia, 2008]. We assume that sediment transport is mainly sand and silt based on the predominance of these grain sizes in accreted basal ice and implement the sand bed equations of van Rijn [1984a, 1984b] to evaluate equilibrium bed load $q_{\mathrm{sw}, \mathrm{e}: \text { bed }}$, and suspended load $q_{\mathrm{sw}, \mathrm{e}: \text { sus }}$. van Rijn's formulas perform well in tests of subaerial fluvial sediment transport [Garcia and Parker, 1991]. Furthermore, the flume experiments through which these formulas are validated have water depths of 3-15 cm [e.g., Abbott and Francis, 1977; Lee and $H s u$, 1994] that are within the range of water depths expected along overdeepenings [e.g., Alley et al., 1998; Creyts and Clarke, 2010]. The lack of a lid in the openwater flume experiments is a critical difference, and such a lid will change sediment transport (H. Ikeda, personal communication, 2005). To our knowledge, this topic has not been explored adequately in the literature, so we choose to ignore the effects of a lid. Total equilibrium load is the sum, $q_{\mathrm{sw}, \mathrm{e}}=q_{\mathrm{sw}, \mathrm{e}: \text { sus }}+q_{\mathrm{sw}, \mathrm{e}: \text { bed }}$. We include an abbreviated explanation of this formulation and implementation in the Supplementary Online Material (see sections S2 and S3).

[37] In equation (7), the adaptation length $L_{\mathrm{s}}$ is a spatial measure of how close the sediment load is to equilibrium. Small values indicate near-equilibrium flow. For larger grain sizes, the adaptation length decreases with increasing size such that bed load is nearly always in equilibrium [Phillips and Sutherland, 1989]. For smaller grain sizes, the adaptation length depends on the particle fall velocity and the turbulence structure of the flow [e.g., van Rijn, 1984b]. Different values are used for $L_{\mathrm{s}}$ depending on scale of a feature of interest (e.g., ripple vs. dune vs. bar), whether the data are from field or flume studies, and on relevant grain sizes [e.g., Armanini and di Silvio, 1988; Phillips and Sutherland, 1989; Wu et al., 2004; Yalin, 1972]. Because of the ambiguity in choosing a length scale, $L_{\mathrm{s}}$ becomes an arbitrary parameter. For both suspended and bed load, we choose $L_{\mathrm{s}}=\Delta \mathrm{s}(t)$ at any time step to maintain continuity in the sediment mass balances.

\subsubsection{Sediment Freeze-on}

[38] Mass balance of the accreted layer written as an evolution of the concentration of sediment in the ice $\lambda_{\mathrm{i}}$, is,

$$
\frac{\partial \lambda_{\mathrm{i}}}{\partial t}= \begin{cases}0 & \widetilde{m}>0 \\ -\frac{1}{Z_{\mathrm{iW}}}\left(\lambda_{\mathrm{i}} \frac{\partial Z_{\mathrm{iW}}}{\partial t}+\frac{\widetilde{\Psi}_{\mathrm{i}}}{\rho_{\mathrm{s}}}\right) & \widetilde{m}<0\end{cases}
$$

where $Z_{\text {iw }}$ is the thickness of accreted ice. When ice melts, the concentration of sediment does not change. The change in concentration matters only when ice with a different sediment concentration is accreted. We ignore ice deformation and sliding, so that there is also no ice velocity in equation (8). This assumption is consistent with the mass balance equations presented previously.

[39] Frazil ice is commonly observed at vents discharging subglacial water near overdeepenings [Lawson et al., 1998; Roberts et al., 2002; Tweed et al., 2005], and the growth and coalescence of these platy ice crystals possibly play a role in sediment trapping and accretion [Lawson et al., 1998; Cook et al., 2012]. Because the dynamics of frazil ice and how it aggregates to form structures is complex [e.g., Daly, 1984; Hammar and Shen, 1995], we simply assign the supply of sediment to or from the ice $\widetilde{\Psi}_{\mathrm{i}}$, as

$$
\widetilde{\Psi}_{\mathrm{i}}=\left\{\begin{array}{ccc}
\frac{\lambda_{\mathrm{i}} \rho_{\mathrm{s}}}{\left(1-\lambda_{\mathrm{i}}\right) \rho_{\mathrm{i}}} & \text { for } & \widetilde{m}>0 \\
C_{\mathrm{i}} \lambda_{\mathrm{b}} \widetilde{m} & \text { for } & \widetilde{m}<0
\end{array}\right.
$$

where $C_{\mathrm{i}}$ is a factor that allows for sediment to be preferentially trapped by accreting ice. An assumption inherent in the mass supply term in equation (9) is that there is no sediment in the water in the ice pore space. Ideally, $C_{\mathrm{i}}$ would be related to the degree of supercooling, the flow Reynolds number (or alternatively, the turbulence intensity, which has been linked to frazil ice formation [Daly, 1984]), as well as the concentration of sediment in the water. Because there is no specific rule available for sediment entrainment, we assign the accreted sediment concentration as that of the subjacent water with $C_{\mathrm{i}}=1$. 


\section{CREYTS ET AL.: SEDIMENT REDISTRIBUTION AND GLACIOHYDRAULIC SUPERCOOLING}

\subsection{Ice Thickness}

[40] Glacier thickness will decrease or increase as basal ice is melted or accreted. The rate of change of glacier thickness $Z_{\mathrm{i}}$, is bed. Furthermore, shear is partitioned between mobile and immobile grain sizes along the bed. Typically, form roughness results from bedforms along flow; however, we use it to capture the immobile fraction of the bed. From the

$$
\frac{\partial Z_{\mathrm{i}}}{\partial t}=-\frac{1}{n_{\mathrm{i}} \rho_{\mathrm{w}}+\left(1-n_{\mathrm{i}}\right)\left(1-\lambda_{\mathrm{si}}\right) \rho_{\mathrm{i}}+\left(1-n_{\mathrm{i}}\right) \lambda_{\mathrm{si}} \rho_{\mathrm{s}}}\left\{\left[1+\frac{n_{\mathrm{i}} \rho_{\mathrm{w}}}{\left(1-\lambda_{\mathrm{i}}\right)\left(1-n_{\mathrm{i}}\right) \rho_{\mathrm{i}}}\right] \widetilde{m}+\widetilde{\Psi}_{\mathrm{i}}\right\},
$$

$$
\frac{\partial Z_{\mathrm{i}}}{\partial t}=-\frac{1}{\left(1-n_{\mathrm{i}}\right) \rho_{\mathrm{i}}+n_{\mathrm{i}} \rho_{\mathrm{w}}}\left\{\left[1+\frac{n_{\mathrm{i}} \rho_{\mathrm{w}}}{\left(1-\lambda_{\mathrm{i}}\right)\left(1-n_{\mathrm{i}}\right) \rho_{\mathrm{i}}}\right] \widetilde{m}+\left[1-\left(1-n_{\mathrm{i}}\right)\left(1-\frac{\rho_{\mathrm{i}}}{\rho_{\mathrm{s}}}\right)\right] \widetilde{\Psi}_{\mathrm{i}}\right\},
$$

where equation (10a) holds for melting of the ice roof $(\widetilde{m}>0)$ and equation $(10 \mathrm{~b})$ holds for ice accretion $(\widetilde{m}<0)$. Ice thickness does not change when the melt rate is exactly zero. Equations (10a) and (10b) are an algebraic manipulation of the mass balance of the glacier ignoring processes on the surface and assuming that ice density and porosity are constant. As ice accretes or melts, sediment is either trapped in the forming ice or released to the subglacial hydraulic system, respectively.

[41] Accreted ice thickness $Z_{\text {iw }}$ also changes when ice melts or accretes to the base of a glacier (Figure 2). For most conditions, the rate of change of accreted ice is exactly equal to the rate of change of total ice thickness. Thus, $\partial Z_{\mathrm{i}} / \partial t=\partial$ $Z_{\mathrm{iw}} / \partial t$ from equations (10a) and (10b). Exceptions occur if melting occurs beneath the glacier but there is no accreted ice (i.e., $Z_{\mathrm{iw}}=0$ ), in this case a $\partial Z_{\mathrm{iw}} / \partial t$ can be calculated by equation (10a) but $\partial Z_{\mathrm{iw}} / \partial t=0$.

[42] If there is melting along the ice ceiling from water flow $(\widetilde{m}>0)$, the supply term in equation (9) has a simple form, and the rate of change of ice thickness simplifies to,

$$
\frac{\partial Z_{\mathrm{i}}}{\partial t}=-\frac{1}{\left(1-\lambda_{\mathrm{i}}\right)\left(1-n_{\mathrm{i}}\right) \rho_{\mathrm{i}}} \widetilde{m}
$$

[43] For $\lambda_{\mathrm{si}}=0$, this equation has the reassuring effect of being exactly equal to the clear water equation [Creyts and Clarke, 2010, equation (4a)].

\subsection{Auxiliary Relations}

[44] To solve equations (2a) to (2d) auxiliary relations for the partitioning of $\tau_{0}$ and the evaluation of both $\widetilde{\Psi}_{\mathrm{i}}$ and $\widetilde{\Psi}_{\mathrm{b}}$ are necessary. Relations for $\widetilde{m},(\partial H / \partial t)_{\text {close }}$, as well as hydraulic cross section, hydraulic perimeter, melting perimeter, and flow path are not presented here. We refer the reader to Creyts and Clarke [2010] for details of implementation of those relations.

\subsubsection{Viscous Dissipation and Shear Partitioning}

[45] Shear stress from the flowing water will be partitioned between the overlying ice roof and the underlying
Darcy-Weisbach formulation, shear stress along the hydraulic perimeter is

$$
\begin{gathered}
\tau_{0}=\left(\tau_{\mathrm{b}}^{\prime}+\tau_{\mathrm{b}}^{\prime \prime}\right)+\tau_{\mathrm{i}}, \\
=\left(f_{\mathrm{b}}^{\prime}+f_{\mathrm{b}}^{\prime \prime}+f_{\mathrm{i}}\right) \rho_{\mathrm{w}} u^{2} / 16,
\end{gathered}
$$

where we split the total shear $\tau_{0}$, into a linear sum of shear along the ice roof $\tau_{\mathrm{i}}$, shear on mobile grains along the bed $\tau^{\prime}{ }_{b}$, and shear on immobile grains and bedforms $\tau^{\prime \prime}{ }_{b}$ [e.g., Henderson, 1966, chapter 10]. The individual friction coefficients for ice, bed grain resistance, and bed form resistance are $f_{\mathrm{i}}, f^{\prime}{ }_{\mathrm{b}}$, and $f^{\prime \prime}{ }_{\mathrm{b}}$, respectively, where the total friction coefficient is $f_{d}=\left(f_{\mathrm{i}}+f^{\prime}{ }_{\mathrm{b}}+f^{\prime \prime}{ }_{\mathrm{b}}\right) / 2$.

[46] In alluvial rivers, form resistance accounts for bedforms such as ripples, bars, and dunes. In rough streams, large clast sizes account for a significant portion of the form resistance, with relatively little grain shear available to move smaller grain sizes [e.g., Church et al., 1998]. In a subglacial water system, not only are bedforms likely, but, similar to rough streams, large grains can also create significant resistance. Shear stresses on mobile grains will therefore be low, possibly in the range of $10-20 \%$ of the total stress available to the bed.

[47] Based on field evidence discussed above, we assume that the mobile fraction is limited to sand and finer grain sizes. In order to account for all grain sizes, we assume that deformation till lies along the bed. Grain sizes of deformation tills have been described by a fractal distribution with dimension 2.9 [e.g., Hooke and Iverson, 1995; Khatwa et al., 1999]. A dimension of 3.0 would indicate that all grain sizes occupy an equal volume of the till, so that a dimension of 2.9 indicates a modest enrichment in finer grain sizes. To simplify, we adopt a distribution whereby each grain size accounts for an equal area of the bed Creyts and Clarke, [2010]. Our model therefore underpredicts the fraction of sediment eroded, but this is likely inconsequential in terms of magnitude. In equations (12a) and (12b), grain shear is distributed among the mobile fraction of the bed, which is sand and finer grain sizes. All larger grain sizes are static and account for form shear 
in equations (12a) and (12b). Based on our construction of the bed, following Creyts and Clarke [2010], 50\% of the bed is mobile and $50 \%$ is static. In addition, we consider this grain size distribution and shear partitioning as fixed. While there are likely differences in erosion and deposition of different grain sizes, we are not aware of measurements in glacial environments on which to base assumptions. Other factors can affect grain mobility (e.g., local bed surface roughness), but we leave such investigations for future studies. To simplify, we use grain size $D=2^{-\Phi} \times 0.001 \mathrm{~m}$ with integer values of the common $\Phi$-scale, $\Phi=-9,-8, \ldots, 8$, corresponding to a bed of loose clay- to boulder-sized particles [Creyts and Clarke, 2010]. Grain sizes larger than sand are assumed immobile, and grain sizes smaller than sand are assumed to move in suspension.

[48] Few estimates of friction factors exist for the subglacial water system that we consider here. Calibrated models similar to the one we present show that subglacial floods have friction coefficients in the range near subaerial fluvial systems [Clarke, 2003]. Therefore, we set $f_{\mathrm{b}}=f_{\mathrm{i}}=0.16$ (Table 1 ). This is equivalent to the friction factor value used in Creyts and Clarke [2010]. Both $f_{\mathrm{b}}$ and $f_{\mathrm{i}}$ likely adjust to flow conditions, but we do not consider these dynamic effects.

\subsection{Reduction to Steady State}

[49] Simple behaviors of the system become apparent when steady state is assumed. In this case, water depth, water pressure, water velocity, and water temperature do not change with time. We thus ignore equations (2a) and (2b). The velocity is derived from equations (2c), (12a), and (12b),

$$
u=-\sqrt{\frac{4 H}{\rho_{\mathrm{w}} f_{d}}}\left|\frac{\partial \phi}{\partial s}\right|^{-1 / 2} \frac{\partial \phi}{\partial s},
$$

where we have ignored the inertial and impulse terms. To simplify the steady-state temperature equation, we keep only the divergence term, the latent heat term, and the viscous dissipation term. All other terms are ignored. We make the assumption that the divergence term $u \partial T_{\mathrm{w}} / \partial s$ can be replaced using the chain rule with $u \partial p_{\mathrm{w}} / \partial s \partial T / \partial p$. A further assumption is that the water is at the pressure melting point, so that $\partial T / \partial p=\beta$, the Clausius-Clapeyron coefficient. Solving the temperature balance for steady-state melt rate gives

$$
\widetilde{m}=-\frac{H u}{L}\left(\rho_{\mathrm{w}} c_{\mathrm{w}} \beta \frac{\partial p_{\mathrm{w}}}{\partial s}+\frac{\partial \phi}{\partial s}\right) .
$$

Additional details of the derivation of the velocity and melt rate are given by Creyts and Clarke [2010, section 3.4].

[50] Furthermore, if we set water pressure to ice overburden pressure such that effective pressure $p_{e}=p_{\mathrm{i}}-p_{\mathrm{w}}=0$, the crossover from melting to freezing $\widetilde{m}=0$ becomes a function of surface and bed slopes $\mathcal{R}$. The critical ratio of these slopes, $\mathcal{R}_{c r}$, then becomes,

$$
\mathcal{R}_{c r}=-\frac{\sin \alpha_{\mathrm{w}}}{\sin \alpha_{\mathrm{r}}}=-\frac{\left(1+\beta c_{\mathrm{w}} \rho_{\mathrm{w}}\right)}{\rho_{\mathrm{w}}-\left(1+\beta c_{\mathrm{w}} \rho_{\mathrm{w}}\right) \rho_{\mathrm{i}}} \simeq-\frac{\tan \alpha_{\mathrm{w}}}{\tan \alpha_{\mathrm{r}}},
$$

with $\alpha_{\mathrm{w}}$ being the local angle of the subglacial water system from the horizontal, $\alpha_{\mathrm{r}}$ the glacier surface slope angle such that $\tan \alpha_{\mathrm{w}}$ and $\tan \alpha_{\mathrm{r}}$ are the slopes of the basal water system and glacier surface slope. For reasonable choices of the
Clausius-Clayperon coefficient that governs pressure melting, specific heat, and mass densities of ice and water, $R_{c r}$ lies in the range -2.02 to -1.20 for pure and air-saturated water, respectively, owing to the subtle differences in choice of parameter values, particularly water density [Alley et al., 1998; Creyts and Clarke, 2010; Hooke, 1991; Röthlisberger and Lang, 1987]. For parameter choices in Table $1, R_{c r}$ is -1.70 .

[51] We assume that the water always carries an equilibrium sediment load so that the instantaneous sediment flux is always equal to the equilibrium sediment flux, $q_{\mathrm{s}}=q_{\mathrm{sw}, \mathrm{e}}$. The water velocity in equation (13) is the only variable necessary to solve for sediment transport provided that the water depth is known (see Supplementary Online Material). Any local change in sediment load must be accommodated by either deposition along the bed or accretion in ice for steadystate water flow. Because the water depth and sediment concentration do not change with time, the sedimentation rate along the bed can be derived from equations (4a), (4b), and (6),

$$
\frac{\partial z_{\mathrm{b}}}{\partial t}=-\frac{1}{1-n_{\mathrm{b}}}\left(\frac{\partial q_{\mathrm{s}}}{\partial s}-\frac{\widetilde{\Psi}_{\mathrm{i}}}{\rho_{\mathrm{s}}}\right)
$$

where equation (9) determines the supply of sediment to the ice. If we further assume that there is no sediment in the ice that can be supplied to the water, then the canonical 1-D Exner equation is obtained [e.g., Henderson, 1966, chapter 10].

\section{Numerical Method}

[52] Together, equations (2), (4), (6), (8), and (10) form a system of equations for water depth $H$, water pressure $p_{\mathrm{w}}$, water velocity $u$, water temperature $T_{\mathrm{w}}$, sediment concentra-

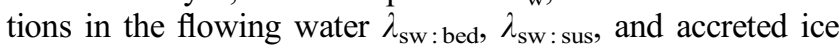
thickness $Z_{\mathrm{i}}$, elevation of the subglacial water-bed interface $z_{\mathrm{b}}$, and sediment concentrations in the ice $\lambda_{\mathrm{si} \text { : bed }}$ and $\lambda_{\mathrm{si} \text { : sus }}$, respectively. This yields a total of 10 equations for 10 unknowns subject to the auxiliary relations.

[53] We use a one-dimensional finite-volume scheme and discretize variables on a staggered grid to solve the system of 10 equations. We discretize over the length of a terminal overdeepening. Fields $\left(H, p_{\mathrm{w}}, T_{\mathrm{w}}, Z_{i}, \lambda_{\mathrm{sw} \text { : bed }}, \lambda_{\mathrm{sw}: \text { sus }}, z_{\mathrm{b}}, \lambda_{\mathrm{si}: \text { bed }}\right.$, and $\left.\lambda_{\text {si : sus }}\right)$ are collocated on a centered grid, whereas velocity $u$ and its associated fluxes are located on the staggered grid. Any quantity that needs to be moved from one grid to the other is averaged using water discharge to conserve mass.

[54] For the sediment concentration in basal ice, we make the simplification that it has a constant vertical value. Field evidence including stratification of basal layers with heterogeneous grain size distributions indicates that the sediment concentration profile is not constant [e.g., Cook et al., 2007; Lawson, 1979; Lawson et al., 1998; Roberts et al., 2002]. However, in order to trace sediment concentration via an algorithm, the profile would need to be smooth [e.g., Staniforth and Côté, 1991]. Additionally, tracing sediment concentrations via stretched grids would introduce numerical diffusion such that mass is not necessarily conserved [e.g., Hildes, 2001].

\subsection{Boundary Conditions}

[55] We implement the same upstream conditions on water flow used by Creyts and Clarke [2010] whereby an upstream 


\section{CREYTS ET AL.: SEDIMENT REDISTRIBUTION AND GLACIOHYDRAULIC SUPERCOOLING}

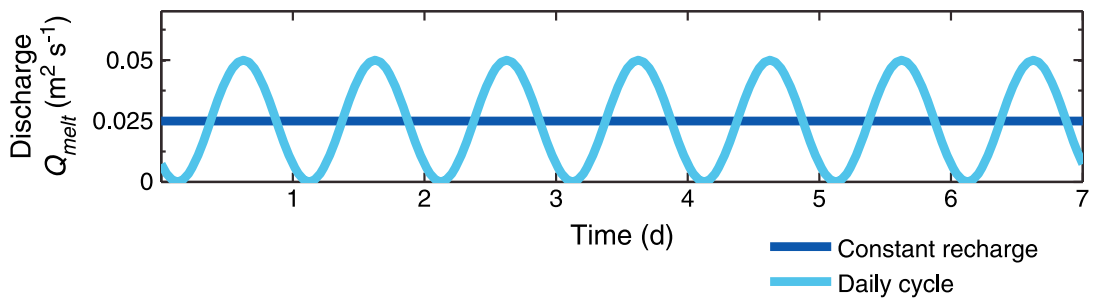

Figure 3. Recharge into the feeder crevasse for constant discharge (dark blue) given by equation (18a) and a daily cycle approximated as a sine wave (light blue) given by equation (18b). Both curves have the same average value.

crevasse feeds the subglacial hydrology. Water flows into the crevasse at a flow rate that is prescribed, and the crevasse acts as a small upstream reservoir. This condition is intended to be a reasonable substitute for water delivery to the upstream end of a terminal overdeepening [Creyts and Clarke, 2010]. We expect moulins, crevasses, and fractures to feed subglacial water flow. The upstream feeder crevasse is a simplified but straightforward representation of actual glacier hydrology.

[56] Pressure in the crevasse $p_{c}$ evolves according to

$$
\begin{gathered}
\frac{d p_{c}}{d t}=\rho_{\mathrm{w}} g \frac{d Z_{c}}{d t}, \\
\frac{d Z_{c}}{d t}=\frac{Q_{\mathrm{melt}}-Q_{\mathrm{w}}}{A_{c}},
\end{gathered}
$$

where $Z_{c}$ is the water depth in the crevasse, $Q_{\text {melt }}$ is the surface recharge rate into the crevasse, $Q_{\mathrm{w}}$ is discharge to the subglacial system, and $A_{c}$ is a representative crevasse cross-sectional area which we set to $10 \mathrm{~m}^{2}$ (Table 1). Furthermore, inlet temperature of the crevasse $T_{c}$ is set to the pressure melting point via

$$
\frac{d T_{c}}{d t}=\beta \frac{d p_{c}}{d t}
$$

[57] In these equations, the pressure difference from the crevasse to the subglacial system drives water into the overdeepening. In assigning $Q_{\text {melt }}$, we use both constant recharge conditions and a diurnal cycle as end members to discuss how the subglacial system reacts to upstream forcing. We modify the surface recharge from Creyts and Clarke [2010] to

$$
\begin{gathered}
Q_{\text {melt }}=Q_{\text {ref }}, \quad \text { constant recharge } \\
Q_{\text {melt }}=Q_{\text {ref }} \sin \left(\frac{2 \pi(t-9 \times 3600)}{24 \times 3600}\right) \text { daily cycles, }
\end{gathered}
$$

\begin{tabular}{|c|c|c|c|}
\hline Parameter & Value & Units & Notes \\
\hline \multicolumn{4}{|c|}{ Empirical constants: } \\
\hline$A$ & $6.8 \times 10^{-24}$ & $\mathrm{~Pa}^{-n} \mathrm{~s}^{-1}$ & Flow law coefficient [Paterson, 1994, p. 97] \\
\hline$c_{\mathrm{w}}$ & 4217.6 & $\mathrm{~J} \mathrm{~kg}^{-1} \mathrm{~K}^{-1}$ & Specific heat of water at constant pressure \\
\hline$g$ & 9.81 & $\mathrm{~m} \mathrm{~s}^{-2}$ & Gravitational acceleration \\
\hline$K_{\mathrm{w}}$ & 0.5610 & $\mathrm{~W} \mathrm{~m} \mathrm{~m}^{-1} \mathrm{~K}^{-1}$ & Thermal conductivity of water \\
\hline$L$ & $3.336 \times 10^{5}$ & $\mathrm{~J} \mathrm{~kg}^{-1}$ & Latent heat of water \\
\hline$n$ & 3.0 & [unitless] & Flow exponent [Nye, 1953; Paterson, 1994] \\
\hline$\rho_{\mathrm{i}}$ & 916.7 & $\mathrm{~kg} \mathrm{~m}^{-3}$ & Mass density of ice \\
\hline$\rho_{\mathrm{s}}$ & 2500.0 & $\mathrm{~kg} \mathrm{~m}^{-3}$ & Mass density of dry sediment \\
\hline$\rho_{\mathrm{w}}$ & 1000.0 & $\mathrm{~kg} \mathrm{~m}^{-3}$ & Mass density of water at $0^{\circ} \mathrm{C}$ \\
\hline$\mu$ & $1.781 \times 10^{-3}$ & Pa s & Viscosity of water at $0{ }^{\circ} \mathrm{C}$ \\
\hline \multicolumn{4}{|c|}{ Derived constants: } \\
\hline $\operatorname{Pr}$ & 13.39 & [unitless] & Prandtl number \\
\hline$\beta$ & $-7.44 \times 10^{-8}$ & $\mathrm{~K} \mathrm{~Pa}^{-1}$ & Pressure melting coefficient; equation (17c) \\
\hline$R_{c r}$ & -1.70 & [unitless] & $\begin{array}{l}\text { Threshold bed to surface slope ratio for } \\
\text { glaciohydraulic supercooling. }\end{array}$ \\
\hline \multicolumn{4}{|c|}{ Model parameters: } \\
\hline$A_{c}$ & 10 & $\mathrm{~m}^{2}$ & Crevasse cross-sectional area; equation (17b) \\
\hline$C_{\mathrm{i}}$ & 1 & [unitless] & Sediment entrainment coefficient; equation (7) \\
\hline$f_{d}$ & 0.16 & [unitless] & Darcy-Weisbach friction coefficient \\
\hline$f_{\mathrm{b}}^{\prime}$ & 0.0176 & [unitless] & Grain friction coefficient; equation $(12 \mathrm{~b}) ; f_{d}^{\prime} / f_{d}=0.11$ \\
\hline$n_{\mathrm{b}}$ & 0.35 & [unitless] & Porosity of the bed; equation (6); [see van Rijn, 1984a] \\
\hline$\Delta t$ & 30 & $\mathrm{~s}$ & Maximum forward time step \\
\hline$W$ & 1 & $\mathrm{~m}$ & Unit glacier width \\
\hline$\Delta x$ & $2.5-5$ & $\mathrm{~m}$ & Longitudinal grid spacing \\
\hline$Z_{\text {iw }}$ & 0 & $\mathrm{~m}$ & Minimum accreted ice thickness \\
\hline$\gamma_{\mathrm{w}}$ & $1 \times 10^{-7}$ & $\mathrm{~Pa}^{-1}$ & Subglacial water compressibility \\
\hline
\end{tabular}

where equation (18b) is a smoothly varying sinusoid with a minimum at $0300 \mathrm{~h}$ and a maximum at $1500 \mathrm{~h}$. Here and

Table 1. Model Parameters 
elsewhere, the model and results are assumed to have time $t$ taking common units of seconds, but we convert to an appropriate timescale (hours or days) as necessary. Furthermore, we set $Q_{\text {ref }}$ to $0.025 \mathrm{~m}^{2} \mathrm{~s}^{-1}$ with the intent to drive sediment motion. This change in reference discharge is well within the range of water flux observed at glaciers as described in Creyts and Clarke [2010].

[58] Upstream conditions are necessary for both $H$ and $u$. We assume that these do not change significantly from the upstream inlet to the grid. This assumption gives $\partial H / \partial s=0$ and $\partial u / \partial s=0$.

[59] We implement Neumann conditions for the concentration of sediment in water $\left(\lambda_{\mathrm{sw} \text { : sus }}, \lambda_{\mathrm{sw} \text { : bed }}\right)$ such that $\partial \lambda_{\text {sw : sus }} / \partial s=\partial \lambda_{\text {sw : bed }} / \partial s=0$ at the entrance to the subglacial water system. Other options for boundary conditions are that the water enters with an equilibrium sediment load based on the flux from equations determined by the boundary conditions in equations (17a)-(17c). However, such conditions create unwanted results by forcing erosion or deposition of sediment along the upstream grid cells. We have tested numerous variations of boundary conditions with the most satisfactory results coming from the Neumann boundary conditions.

\subsection{Initial Conditions}

[60] Initial values are required for all of the fields $\left(H, p_{\mathrm{w}}\right.$, $T_{\mathrm{w}}, \lambda_{\mathrm{sw} \text { : bed }}, \lambda_{\mathrm{sw} \text { : sus }}, z_{\mathrm{b}}$, and $\left.Z_{\mathrm{i}}\right)$ as well as the water velocity (u). Following Creyts and Clarke [2010], we choose $p_{\mathrm{w}}$ as the ice overburden pressure and $T_{\mathrm{w}}$ as the pressure melting point. We initialize the maximum water depth $H$ as $0.1 \mathrm{~m}$ [e.g., Alley et al., 1998], but note that bed protrusions used in the closure relation occupy a small percent of this maximum value, making the initial, average value $0.087 \mathrm{~m}$. Steady-state conservation of mass dictates that $Q=H W u$. Substituting this value of $H$ (with $W=1 \mathrm{~m}$ ) gives $u=Q_{\text {melt }} / H$ to initialize the velocity.

[61] Using the initial values for $H$ and $u$, we can use van Rijn's formulas to calculate initial values for suspended and bed load sediment concentrations. In general, however, values of $u$ are too low to cause shear stress to exceed a critical value. Consequently, suspended and bed load sediment concentrations in the subglacial water system are initialized to zero. Sediment concentrations in the accreted ice $\left(\lambda_{\text {si : bed }}\right.$ and $\left.\lambda_{\text {si : sus }}\right)$ are assumed to be zero.

[62] For simulations, we use longitudinal flow paths inspired by radar sections of glaciers with overdeepenings with thick ice tapering to the terminus. These sections have adverse slopes that are twice the critical threshold, at the critical threshold, and at half the critical threshold necessary for glaciohydraulic supercooling (Figures 4a and 4b). Additionally, we have included a flat-bedded case (Figure 4b). These are simplified representations of glaciers with overdeepenings such as Matanuska Glacier and Storglaciären. Matanuska stands out as the best studied example of glaciohydraulic supercooling with sediment transport and ice accretion. Lawson et al. [1998] presented two radar sections meant to coincide with subglacial flow paths. Creyts and Clarke [2010] simplified those flow paths, and we use them for simulations. Ice thickness in these sections evolves only from accretion or melt of ice.
Similarly, sedimentation or erosion raises or lowers the bed elevation.

\section{Results}

[63] Here, we present three sets of results to understand how sediment transport in the hydraulic system and accretion via glaciohydraulic supercooling operate along flow. The first results are analytic calculations assuming steady-state water velocity and reduction of the balance equations presented in the previous sections. The other two sets of simulations are time-dependent solutions of all balance equations. The first of these is forced with constant recharge, and the second set is forced with diurnally varying recharge. We use the numerical model to understand what happens from initialization of a drainage system through a summertime melt season. We approximate the melt season with 100 days of results following Creyts and Clarke [2010]. In practice, we run the numerical model for 200 days but only show the first 100 days of the simulation. In every case, the final 100 days of the simulations simply extend the time series with the same or similar rates of long-term change. No additional effects or unreported phenomena are present in the simulations after 100 days. Results show a spectrum of behaviors from the most overdeepened case to the flat-bedded case.

\subsection{Analytic, Steady-State Solutions}

[64] The water flow and sediment transport relations can be solved analytically for steady-state conditions. These solutions require boundary and initial conditions, the longitudinal sections, and the steady-state water velocity described above. Furthermore, we drop the supply of sediment from the ice in equation (6). These solutions yield the simplest behaviors for understanding water flow relative to sediment erosion and deposition.

[65] The melt rate is dependent on the hydraulic gradient and the pressure gradient. Each of the melt rates in Figure $4 \mathrm{~d}$ starts out positive (melting), but only the section at twice the threshold shows a negative rate (freezing) along the overdeepening. This result is expected given that each of the sections was chosen to produce simple thermal behaviors. The transition to freezing is $129 \mathrm{~m}$ from the terminus for the section at twice the threshold.

[66] Sediment transport across all sections decreases with decreasing hydraulic potential gradient (Figure 4e). Notably, the flat-bedded section has the highest transport rates because its bed does not oppose the surface and its surface slope is highest of all sections. Sediment transport lessens for the other three sections because the surface slope lessens and the bed opposes water flow as the ratio $R$ decreases. As shown in Figure $4 \mathrm{f}$, the decrease in sediment load is strongest when the load is highest and the bed rises.

[67] The bed change rates (Figure 4g) are similar to the gradients in total load because these go directly into sedimentation via equation (16). Furthermore, the freezing rate is small at the start of the section at twice the supercooling threshold so that only the ice formed at the start of the overdeepening contains sediment.

[68] In all these examples, the surface of the glacier has constant slope, but the bed has curvature at the onset of the overdeepening. Water velocity lowers as flow starts to ascend 


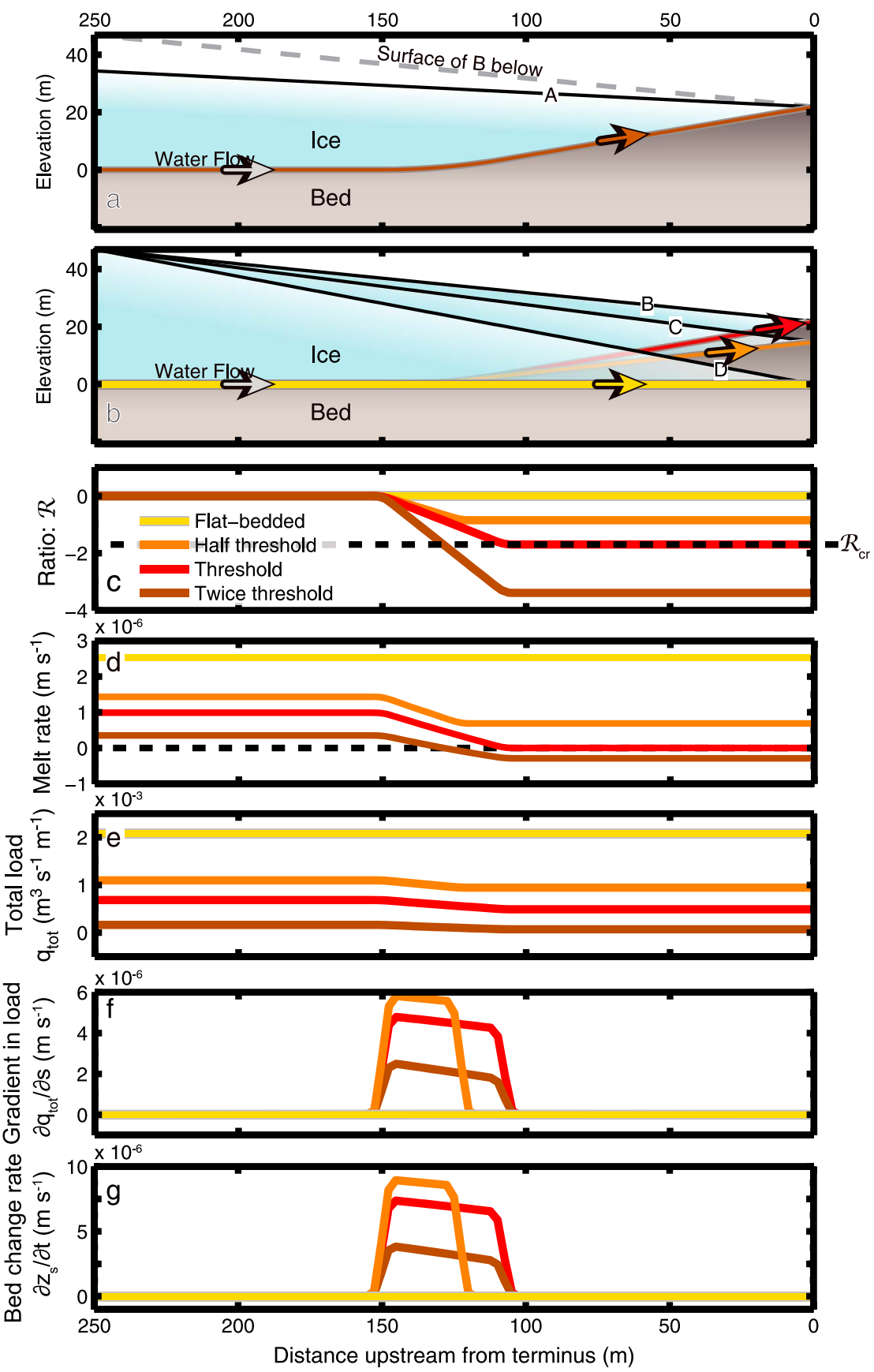

Figure 4. (a) An example overdeepened section (A) with an adverse slope at twice the critical supercooling threshold. (b) Three example longitudinal sections used in simulations with B: an adverse slope at the critical supercooling threshold; C: an adverse slope at half the supercooling threshold; and D: a flat-bedded section. Colored lines along the beds in (a) and (b) correspond to information in the lower panels. Labels $A, B, C$, and D correspond to figure panels for time-dependent results. (c) Surface to bed slope ratio $\mathcal{R}$ for each of the sections. (d) Steady-state melt rate for each section. (e) Steady-state total load (suspended + bed) for each of the sections from the formulation of van Rijn [1984a, 1984b] with parameters from Table 1 and constant water depth. (e) Along-path gradient of total load from (d). (f) Rate of change of the bed for each section.

but becomes constant where the adverse slope reaches a constant value. The reduction of sediment load capacity follows the along-path change in water velocity. The change in capacity yields sediment deposition that varies with bed curvature in this example. The dependence of the van Rijn formulas on water velocity yields this result, and it is a general feature of equilibrium formulas that depend on excess shear stress where the shear stress is velocity dependent. Because the flat-bedded section has no curvature, it maintains a constant sediment flux with neither erosion nor deposition. 


\subsection{Simulations With Steady Upstream Recharge}

[69] Complexity of the results depends on whether the variable varies smoothly or is instantaneous and responds immediately to flow conditions. For example, water depth would be a time-integrated quantity because opening via melt and closing via ice intrusion are slow processes. Water velocity responds rapidly to pressure variations, however.

[70] Downstream flow development depends on the upstream boundary conditions. With a constant recharge of $0.025 \mathrm{~m}^{2} \mathrm{~s}^{-1}$, the water elevation in each of the crevasses evolves to a level below the upstream flotation elevation. Crevasse water elevations reach stable levels of water depth after approximately 30 days, 55 days, 40 days, and 25 days for the sections at twice the critical threshold, at the critical threshold, at half the critical threshold, and for the flatbedded case (Figure 5, column 1, black axes, Table 2). These response times are a result of equilibration of upstream pressure in and recharge to downstream conditions, as we discuss below. Discharge from the upstream boundary crevasse into the subglacial water system matches the recharge into the crevasse. Effluent discharge at the terminus of each of the glacier sections overlays the upstream recharge rate to within the thickness of the lines in Figure 5 (column 1, blue axes).
[71] Water depth records the time-integrated signature of all flow variables because depth responds to ice intrusion, freezing (or melting), and deposition (or erosion) along the bed. These individual processes combine the effects of other variables from the state evolution equations (2a)-(2d). All simulations show a decrease in water depth from the initial conditions. For the twice threshold and threshold cases, the water depth is not monotonic and is largest upstream of the adverse slope (Figures 5a2 and 5b2). The other two sections show a decrease in water depth to values below $0.04 \mathrm{~m}$ once they have reached the transition time at 40 days and 25 days, respectively (Figures $5 \mathrm{c} 2$ and $5 \mathrm{~d} 2$ ). These water depths are relatively constant along the flow.

[72] Bed elevation change is closely coupled to the water depth evolution. For the case where the slope ratio is at twice the threshold (Figure 5a3), the bed elevation change is near zero upstream of the adverse slope. After the transition at 25 days, erosion occurs along the adverse slope and culminates in approximately $0.08 \mathrm{~m}$ of elevation loss at the downstream end. Similarly, erosion occurs along the adverse slope of the threshold section (Figure 5b3), but upstream of the adverse slope, after 100 days, there is net deposition of over $0.125 \mathrm{~m}$ of sediment. This deposition corresponds to the water depth decrease upstream of the overdeepening in Figure $5 b 2$.

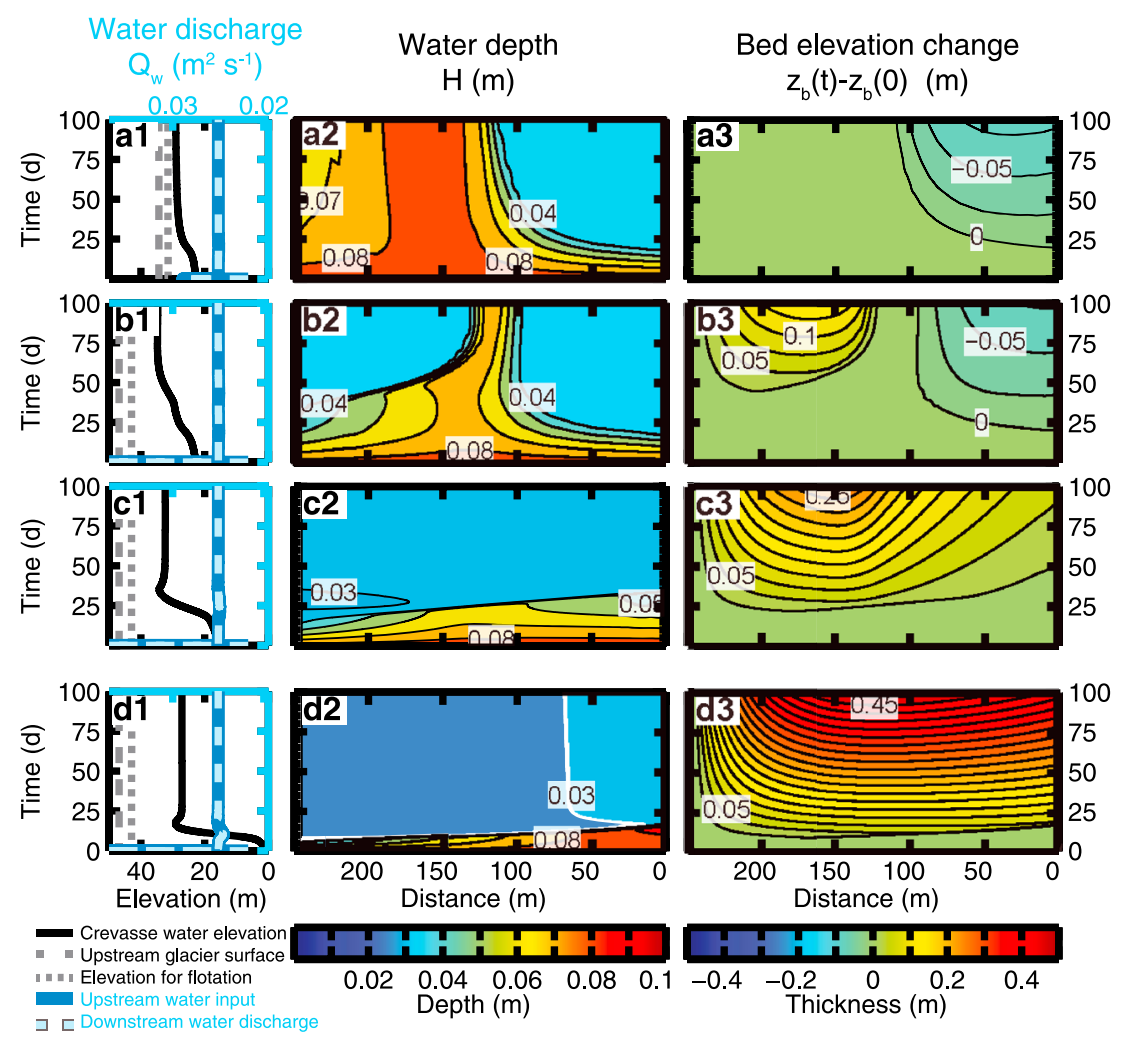

Figure 5. Results for constant upstream forcing. Row a: results for a section with an overdeepening that is twice the critical threshold. Row b: results for a section at the critical threshold for supercooling. Row c: overdeepened section at half the critical supercooling. Row d: flat-bedded section. Column 1: forcing of the subglacial water system. Water discharge (top axis, blue lines) input at the upstream end of the section and downstream discharge. Water elevation in the feeder crevasse (bottom axis, black lines) with flotation and surface elevations as dotted lines. Column 2: water depth evolution along flow in time. Contour interval is $0.01 \mathrm{~m}$. Color scale is the same for all four panels. Column 3: bed elevation change with time. Contour interval is $0.025 \mathrm{~m}$. 


\section{CREYTS ET AL.: SEDIMENT REDISTRIBUTION AND GLACIOHYDRAULIC SUPERCOOLING}

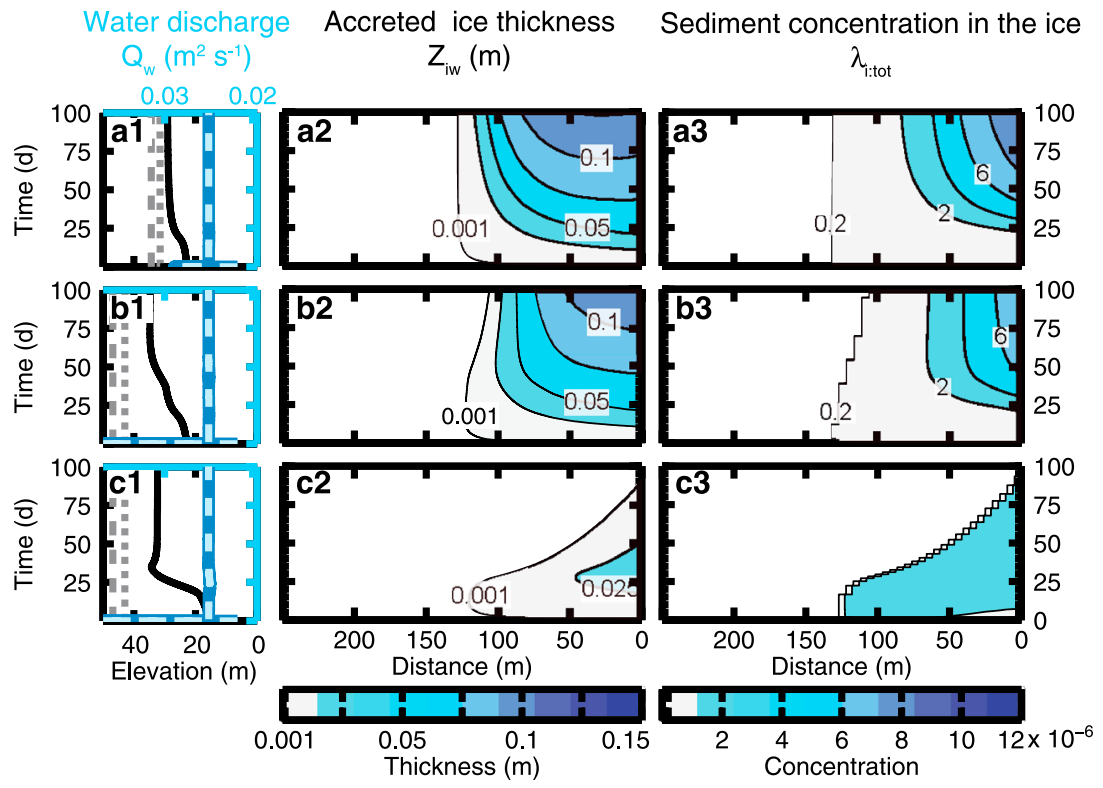

Figure 6. Results for constant upstream forcing. Rows are the same as in Figure 5. There is no accretion for the flat-bedded section so only three sections are relevant. Column 1: forcing of the subglacial water system as in Figure 5. Column 2: accreted ice thickness evolution along flow. Contour interval is $0.025 \mathrm{~m}$ with the exception that the first contour which is $0.001 \mathrm{~m}$. The color scale is the same for all four panels. Column 3: total sediment concentration in the ice. The contour interval is $2 \times 10^{-6}$ with the exception that the first contour is $0.2 \times 10^{-6}$.

[73] The cases at half the supercooling threshold and the flat-bedded case both display deposition along their length for the 100 day simulations (Figures $5 \mathrm{c} 3$ and $5 \mathrm{~d} 3$ ). From about $125 \mathrm{~m}$ along flow continuing along the adverse slope, there is less deposition in the case of the section at half the supercooling threshold. Once the flat-bedded case has adjusted to the inlet conditions over approximately the first $50 \mathrm{~m}$, the total deposition varies subtly in Figure $5 \mathrm{~d} 3$ with a maximum of nearly $0.50 \mathrm{~m}$ over the 100 day simulation.

[74] The total bed elevation change for the overdeepened sections responds to freezing along the adverse slope. Accretion ice forms along the three overdeepened sections (Figures $6 \mathrm{a} 2,6 \mathrm{~b} 2$, and $6 \mathrm{c} 2$ ). In Figures $6 \mathrm{a} 2$ and $6 \mathrm{~b} 2$, the total accretion for the sections at twice the threshold and at the threshold for supercooling is over $0.1 \mathrm{~m}$ for the total length of the simulation. The section at twice the threshold has persistent accretion over the course of the simulation from approximately $125 \mathrm{~m}$ through to the terminus. After an initial phase where accretion starts at $125 \mathrm{~m}$ from the terminus, the section at the critical threshold undergoes some melting of the upstream freeze-on to about $100 \mathrm{~m}$ distance at 100 days. Accretion is ephemeral along the section at half the critical threshold (Figure 6c2). This result is in contrast to the clear water simulations where accretion is persistent [Creyts and Clarke, 2010, Figure 7].

[75] In comparing Figures 5a2, 5a3, and 6a2, it is clear that the locations where the water depth decreases are the locations where freeze-on occurs. Because subglacial discharge is roughly constant along the section, the decrease in water depth causes a speed-up in water flow velocity in order to maintain continuity. This speed-up sends the water velocity above the critical velocity necessary for sediment transport (see Supplementary Online Material). The result is that there is net erosion along the adverse slope where this speed-up occurs. The process also occurs for the section at the critical threshold in Figures 5b2, 5b3, and 6b2. A similar process occurs along the section at half the supercooling threshold where the ephemeral accretion causes a reduction in deposition along the overdeepening (Figures $5 \mathrm{c} 3$ and $6 \mathrm{c} 2$ ). However, because there is a direct trade-off between deposition and freeze-on, the water depth does not appear to be affected by the processes occurring along the adverse slope.

[76] Sediment concentration in the ice follows total accretion but is offset with maximum values at the terminus (Figures $6 \mathrm{~d} 1$ and $6 \mathrm{~d} 2$ ). Concentrations are slightly higher for the simulation at twice the critical threshold approaching $8 \times 10^{-6}$, about $0.02 \mathrm{~g} \mathrm{~L}^{-1}$, than for the simulation at the critical threshold $6 \times 10^{-6}$ (Figure 6d1). Because the accretion is transient for the section at half the supercooling threshold, only nominal amounts of sediment accrete. Because the concentration records the concentration in the water over the time that accretion occurs and then averages this, the high values near the terminus represent high sediment concentrations in the water and longer accretion times. Despite the satisfactory pattern of having the highest sediment concentrations near the terminus, the values are much too low relative to field sites [e.g., Cook et al., 2006; Lawson et al., 1998]. These low values indicate that our parameterization in equation (8) is too conservative and other trapping or filtering mechanisms must be operating.

[77] Changes in water depth, bed elevation, and accretion are related to water flow. The effective pressure, water velocity, and the gradient in sediment transport illustrate how the water flow changes over time relative to the input forcing (Figure 7). The effective pressure gives a measure of how close the water pressure is to ice overburden pressure via equations (2a) to (2d). Each of the simulations begins with zero effective pressure, but because water depth is 


\section{CREYTS ET AL.: SEDIMENT REDISTRIBUTION AND GLACIOHYDRAULIC SUPERCOOLING}

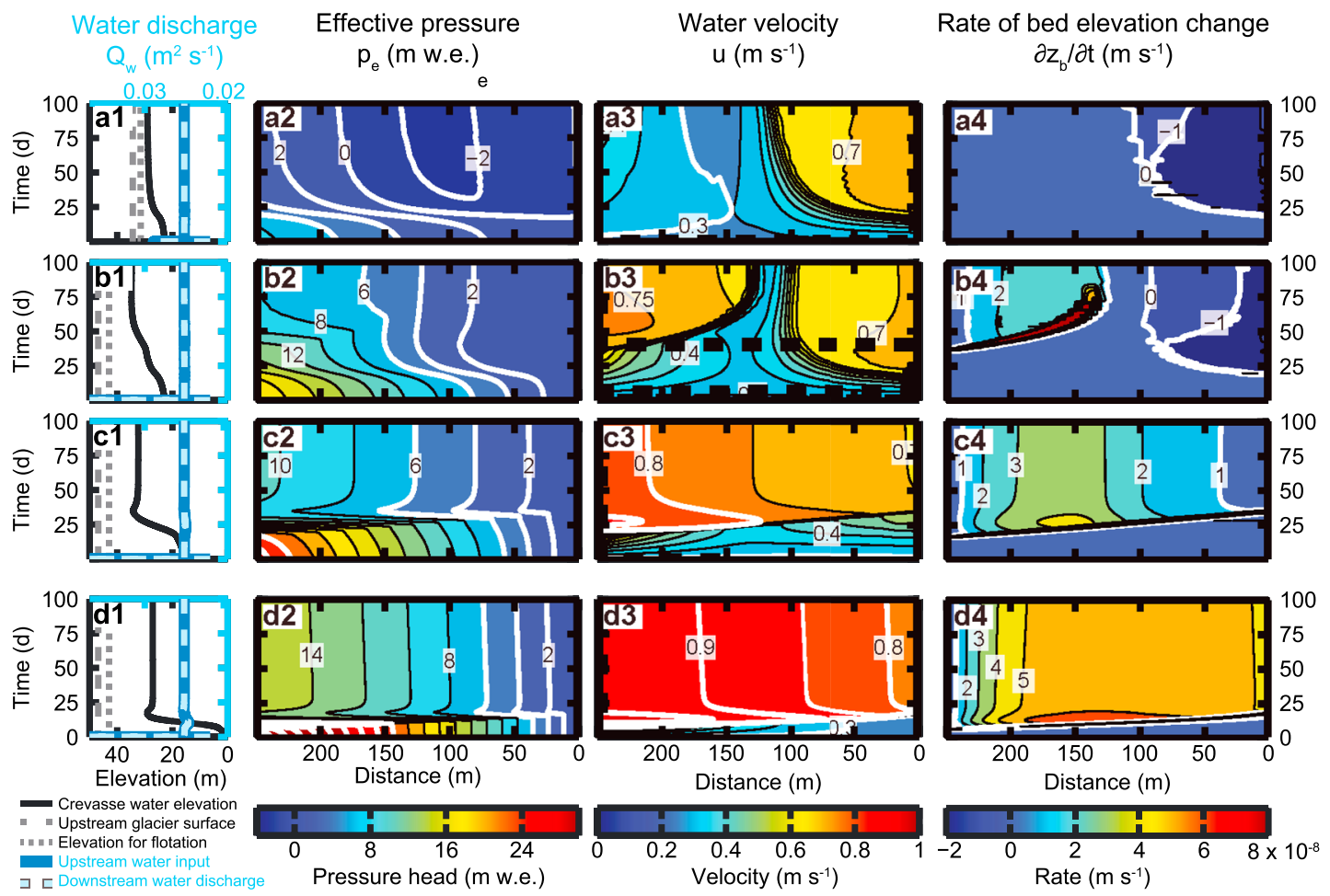

Figure 7. Results for constant upstream forcing. Rows are the same as in Figure 5. Column 1: forcing of the subglacial water system as in Figure 5. Column 2: effective pressure head in the subglacial water system. Contour interval is $2 \mathrm{~m}$ water equivalent (w.e.). Column 3: water velocity through the subglacial system. Contour interval is $0.1 \mathrm{~m} \mathrm{~s}^{-1}$. Black dashed line corresponds to the location of the bottleneck where $\partial \phi / \partial s$ is a minimum. In (a3), the dashed line is at the downstream outlet for all time. In (b3), the bottleneck moves over the duration of the simulation. For (c3) and (d3), the bottleneck remains at the inlet. Column 4: rate of change of the bed. Negative values indicate erosion. Positive values indicate deposition. Contour interval is $1 \times 10^{-8} \mathrm{~m} \mathrm{~s}^{-1}$. Labeled contours are in $10^{-8} \mathrm{~m} \mathrm{~s}^{-1}$.

large, water pressures immediately decline with a simultaneous effective pressure increase. As water depth decreases, effective pressures decrease and the simulations reach a near-steady upstream forcing by the transition time. For the section at twice the supercooling threshold, the effective pressures are negative near the base of the adverse slope (Figure 7a2) once the upstream forcing is near steady. None of the other sections develop negative effective pressures but all have positive effective pressures that indicate water is flowing at pressures less than the ice overburden pressure (Figures $7 \mathrm{~b} 2,7 \mathrm{c} 2$, and $7 \mathrm{~d} 2$ ).

[78] The water velocity is mainly dependent on the hydraulic potential gradient that contains the spatial derivative of the effective pressure. Evolution of water velocity is dependent on the hydraulic potential gradient as it departs from the initial ice overburden pressure. The ice thickness change and the bed elevation change are small throughout the course of each simulation. Where the contours are closely spaced, velocity increases rapidly. For the twice threshold and threshold sections, tight contour spacing indicates strong velocity changes at the upstream end of the adverse slope after the transition time. These are directly correlated with water depth decrease in Figures 5a2 and 5b2. For the case at half the supercooling threshold and the flat-bedded case, once the transition time has passed, the highest velocity values are upstream near the input crevasse and decrease toward the terminus. However, while this decrease is smooth, it does not have a constant slope. The structure of the velocity gives insight to the bed elevation change from erosion and deposition of sediments because erosion and deposition are controlled by thresholds in velocity.

[79] Where the hydraulic potential has large negative values, velocity will be high and this corresponds to a bottleneck in flow [Clarke, 2003; Creyts and Clarke, 2010]. For the twice-threshold section, the bottleneck is always at the downstream end (Figure 7a3). For the threshold section the bottleneck moves back and forth across the section during the 100 day simulation, but the bottleneck moves instantaneously with no time spent along the section, only at the upstream and downstream ends (Figure 7b3). For the other two sections, the bottleneck begins at the downstream end of the section and immediately jumps to the upstream end, where it stays for the remainder of the simulations (Figures $7 \mathrm{c} 3$ and $7 \mathrm{~d} 3$ ).

[80] The rate of change of the bed elevation relates how fast erosion or deposition is occurring. For the steady-state case, deposition and erosion are critically determined by the curvature of the bed, a simplification of the curvature of the hydraulic potential in equation (16). For the timedependent cases, the rate of bed change follows the curvature of the hydraulic potential. Sediment load responds to along-path changes in velocity relative to the sediment entrainment velocity and, thus, to the along-path variations in $\partial \phi / \partial s$. Figures $7 \mathrm{a} 4,7 \mathrm{~b} 4,7 \mathrm{c} 4$, and $7 \mathrm{~d} 4$ capture the rate of bed change that is dependent on a scaled spatial derivative 


\section{CREYTS ET AL.: SEDIMENT REDISTRIBUTION AND GLACIOHYDRAULIC SUPERCOOLING}

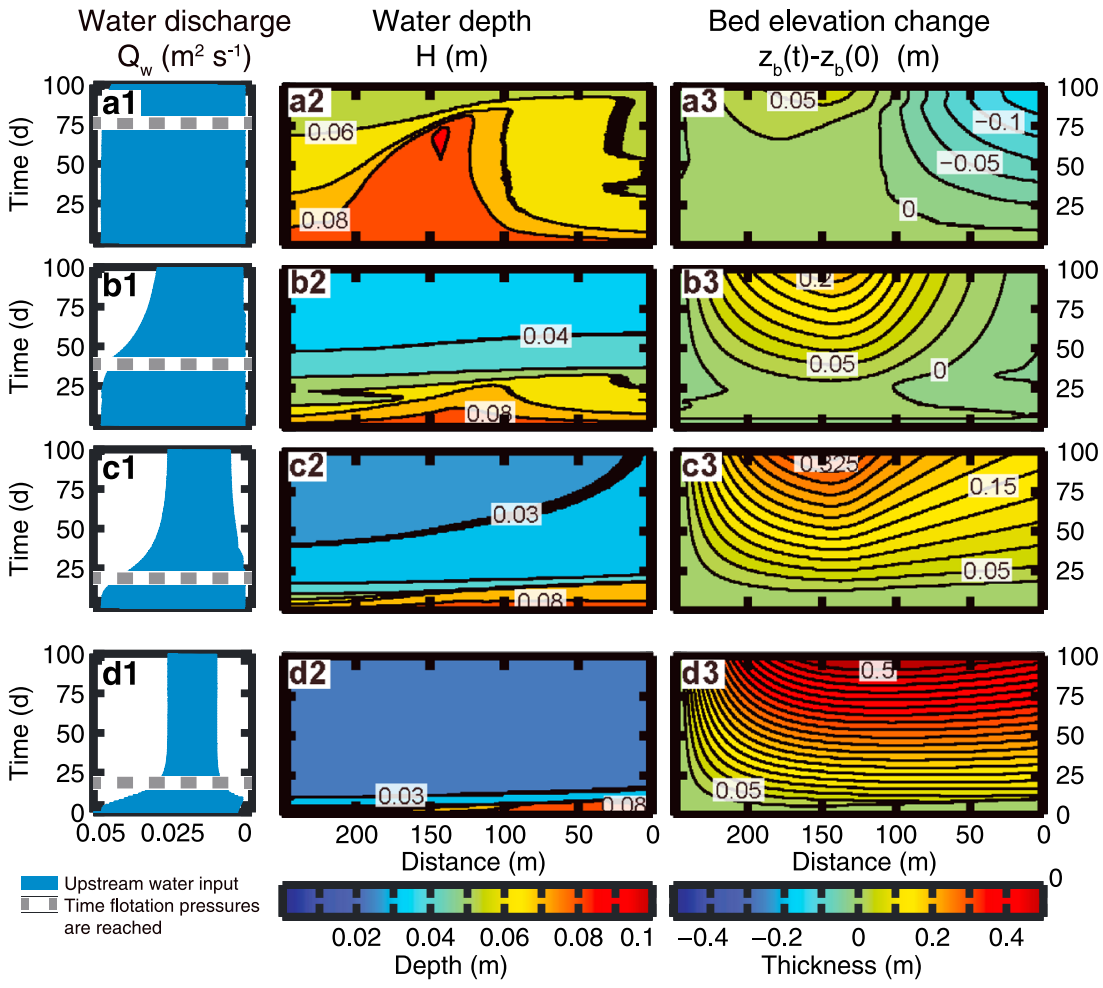

Figure 8. Results for daily forcing. Row a: results for a section with an overdeepening that is twice the critical threshold. Row b: results for a section at the critical threshold for supercooling. Row c: overdeepened section at half the critical supercooling. Row d: flat-bedded section. Column 1: upstream discharge into the subglacial sheet. Blue lines are discharge. Right edge is the daily maximum. Left edge is the nightly minimum. Gray dashed line indicates the time when the crevasse water elevation reaches the glacier surface. Column 2: water depth evolution along flow in time. The contour interval is $0.01 \mathrm{~m}$. Color scale is the same for all four panels. The thickness of the contours arises from subtle changes in the water depth over the course of a diurnal cycle. Column 3: bed elevation change with time. The contour interval is $0.025 \mathrm{~m}$.

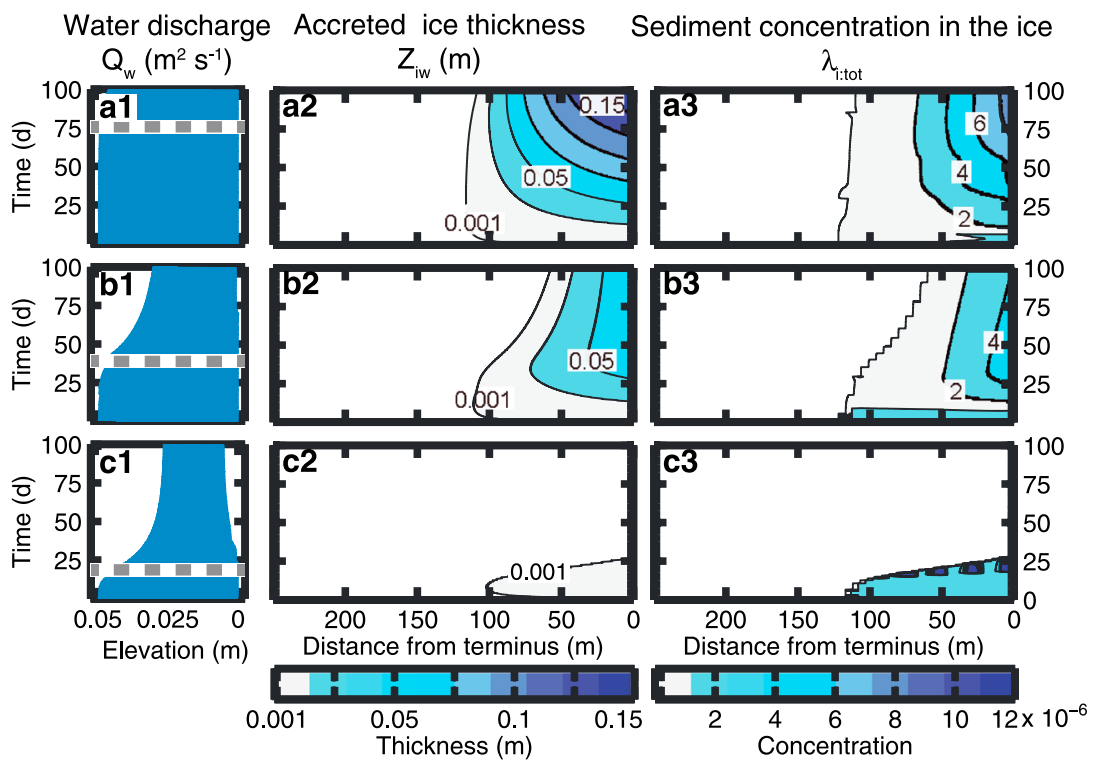

Figure 9. Results for daily upstream forcing. Rows are the same simulations as in Figure 8. Note that there is no accretion for the flat-bedded section so only three sections are relevant. Column 1: forcing of the subglacial water system as in Figure 8. Column 2: accreted ice thickness evolution along flow. Contour interval is $0.025 \mathrm{~m}$ with the exception of the first contour which is $0.001 \mathrm{~m}$. The color scale is the same for all four panels. Column 3: total sediment concentration in the ice. The contour interval is $2 \times 10^{-6}$ with the exception of the first contour is $0.2 \times 10^{-6}$. 
of water velocity (column 3 of Figure 7) or, similarly, a scaled curvature of the effective pressure (column 2 of Figure 7). The rate of bed elevation change is closely coupled to the other variables and ultimately gives the patterns of erosion and deposition along the bed.

\subsection{Simulations With Diurnally Varying Recharge}

[81] The length of summertime varies in glaciated areas. Here we show results for 100 days of integration as a proxy for summertime. Each simulation shows an evolution of the water system over that period. In order to highlight features of the daily cycle of meltwater, we also show daily variations for days 98 to 100 . These variations are representative of how daily forcing affects the subglacial system with the exception that there is some subtle, longer term evolution that overprints the daily variations.

[82] For daily cycles, each of the simulations is forced with a time-varying input of water to the upstream crevasse that follows a sinusoid (Figure 3 ). This forcing translates into a filling and draining of the upstream crevasse on diurnal timescales. The forcing for each of the sections then becomes an envelope of maximum and minimum discharge to the subglacial water system (Figure 8, column 1). The adjustment time for these cases is based on the upstream crevasse reaching its flotation value (Figure 8, column 1, dashed gray lines). The adjustment time is roughly 75 days, 41 days, 22 days, and 21 days for the cases at twice the supercooling threshold, at the supercooling threshold, at half the supercooling threshold, and the flatbedded case, respectively (Table 2 ).

[83] Water depth responds to the diurnal forcing in different ways from the constant recharge cases for the twice-threshold and threshold cases but is quite similar for the half-threshold and flat-bedded cases (Figure 8, column 2). For both the twice-threshold and threshold cases, a constant water depth of about $0.06 \mathrm{~m}$ and $0.04 \mathrm{~m}$ evolves once the transition time is reached (Figures $8 \mathrm{a} 2$ and $8 \mathrm{~b} 2$ ). This contrasts with the constant recharge case where there are variations along flow. The half-threshold and flat-bedded cases in Figures $8 \mathrm{c} 2$ and $8 \mathrm{~d} 2$ have water depths only slightly less than the constant recharge case.

[84] The expectation is that the bed elevation change would be significantly different for the twice-threshold and threshold cases but exhibit near-similar results for the halfthreshold and flat-bedded cases. The results are surprisingly similar for the twice-threshold and threshold cases, however, with erosion along the adverse slope (Figures $8 \mathrm{a} 3$ and $8 \mathrm{~b} 3$ ). There are subtle differences in variation along flow with time. For example, there is some deposition upstream of the adverse slope for the twice-threshold case and there is

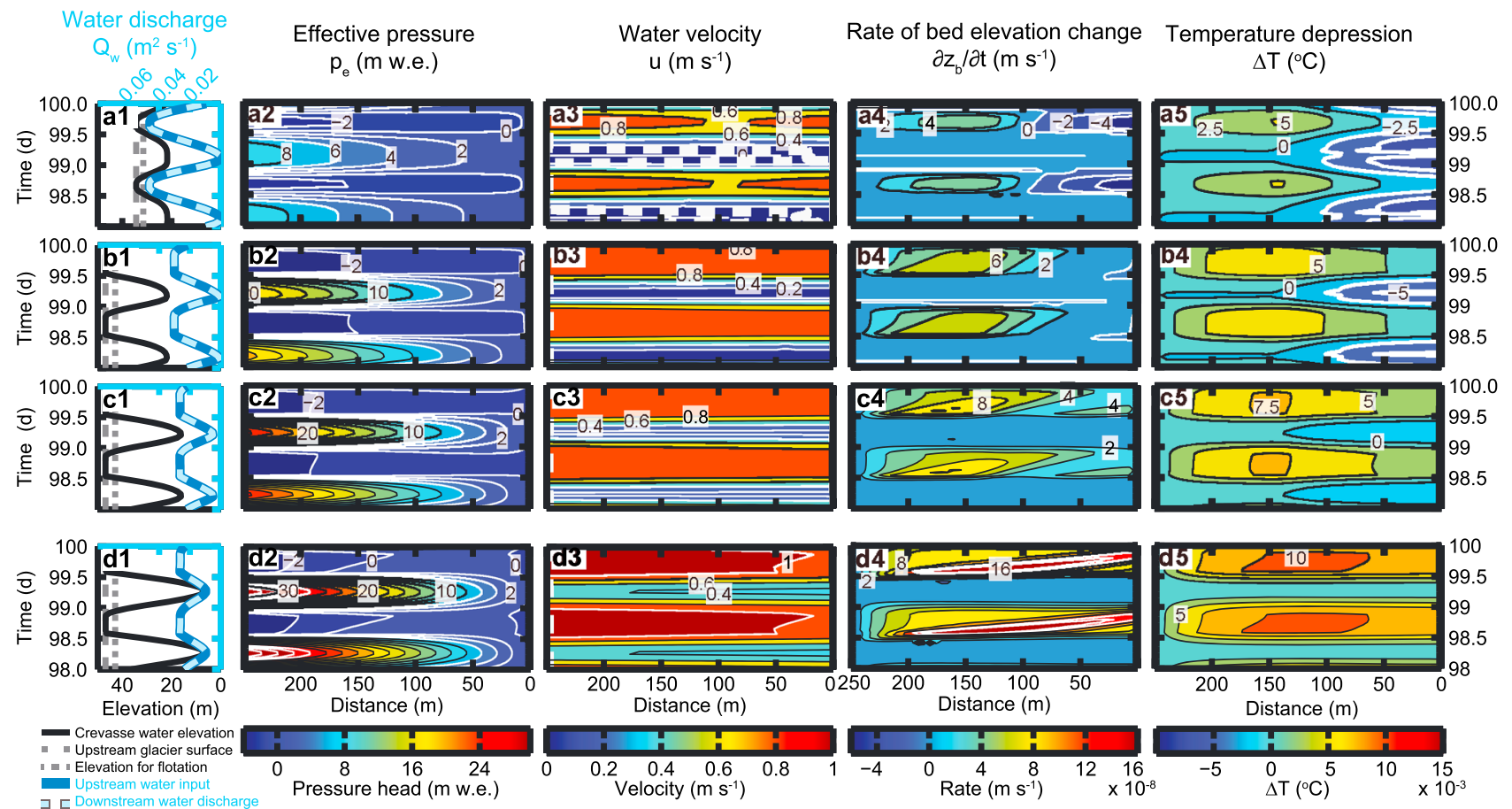

Figure 10. Results for daily upstream forcing for 2 days. Rows are the same simulations as in Figure 8 . Column 1, upper blue axes: water discharge through the subglacial system. Inflow from the upstream feeder crevasse is represented by dark blue lines. Light dashed lines are the effluent water flow at the outlet. Lower black axes: water elevation in the feeder crevasse. Gray dashed lines are the flotation and glacier surface elevations. Column 2: effective pressure head in the subglacial water system. Contour interval is $2 \mathrm{~m}$ water equivalent ( $\mathrm{m}$ w.e.). Column 3: water velocity through the subglacial system. Contour interval is 0.1 . White dashed line corresponds to the location of the bottleneck. In (a3), the bottleneck (dashed line) migrates downstream during nighttime and upstream during daytime. For (b3), (c3), and (d3), the bottleneck remains at the inlet. Column 4: gradient in total sediment flux. Contour interval is $6 \times 10^{-9} \mathrm{~m} \mathrm{~s}^{-1}$. Labeled contours are in $10^{-9} \mathrm{~m} \mathrm{~s}^{-1}$. Column 5: temperature depression. Contour interval is $2.5 \times 10^{-3 \circ} \mathrm{C}$. Labeled contours are in $10^{-3 \circ} \mathrm{C}$. These results are included in the Supplementary Online Material as animations. 
Table 2. Adjustment Times for Simulations Results in Days ${ }^{\mathrm{a}}$

\begin{tabular}{lccc}
\hline $\begin{array}{l}\text { Longitudinal } \\
\text { Section }\end{array}$ & $\begin{array}{c}\text { Upstream } \\
\text { Recharge Type Adjustment Time }\end{array}$ & $\begin{array}{c}\text { Clear Water } \\
\text { Sediment Transport } \\
\text { Adjustment Time }\end{array}$ \\
\hline $\begin{array}{l}\text { Twice } \\
\text { threshold }\end{array}$ & Constant & 56 & 27 \\
Threshold & Constant & 56 & 35 \\
Half threshold & Constant & 29 & 25 \\
Flat-bedded & Constant & $\underline{15}$ & $\frac{11}{25}$ \\
Average & & 39 & 74 \\
\hline $\begin{array}{l}\text { Twice } \\
\text { threshold }\end{array}$ & Daily & 59 & 41 \\
Threshold & Daily & 79 & 22 \\
Half threshold & Daily & 149 & 21 \\
Flat-bedded & Daily & $\frac{38}{40}$ \\
Average & & 81 &
\end{tabular}

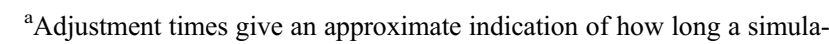
tion takes to reach stable input conditions from the upstream crevasse. Clear water adjustment times are from Creyts and Clarke [2010].

slightly more erosion along the adverse slope (Figure 8a3). For the threshold case, deposition increases to $0.1 \mathrm{~m}$ upstream of the adverse slope, and erosion occurs farther along the adverse slope relative to its onset. The other two sections have similar patterns of bed elevation change along flow relative to the simulations with constant forcing, but the magnitudes are slightly larger (Figures $8 \mathrm{c} 3$ and $8 \mathrm{~d} 3$ ).

[85] Ice accretion is slightly different for the cases with daily forcing. For the twice-threshold section, more ice has accreted after 100 days $(\sim 0.15 \mathrm{~m})$ (Figure $9 \mathrm{a} 2)$. Both the threshold and half-threshold sections have less accretion. Transient accretion for the half-threshold section persists only to the adjustment time (Figures $9 \mathrm{~b} 2$ and 9c2). The shallow water depth increases local heat production to melt this ice.

[86] Maximum accreted sediment concentrations are offset downstream relative to accreted ice volumes. Maximum concentration values occur at the terminus (Figure 9, column 3). The sediment concentrations are higher for the twice-threshold section, but are lower for the threshold section. The halfthreshold section has negligible accretion that melts off once the transition time is reached. Concentrations are orders of magnitude lower than measurements from field sites.

[87] For the final 2 days of numerical results, the upstream forcing shows how crevasse water depth and discharge to the subglacial water system are related (Figure 10, column 1). For the twice-threshold section in Figure 10a1, crevasse water elevation rises during the morning, exceeds the flotation pressure in the afternoon, and then falls during evening before reaching a minimum value during nighttime. Some of the input water to the feeder crevasse overflows so that not all water flux is transmitted along the base of the glacier. Nightly minima correspond to the outlet elevation at the downstream end of the glacier section. Subglacial discharge lags the crevasse water forcing by a few hours, and the nighttime minimum in pressure corresponds with zero discharge through the subglacial hydraulic system.

[88] Similar features are seen for the other three sections (Figures 10b1, 10c1, and 10d1). The morning rise in water elevation takes approximately the same amount of time, but the length of time that the crevasse stays at the flotation level is longer, approaching half a day. In the evening, the crevasse drains, reaching a nightly minimum that is the terminus exit elevation for the threshold section, and water discharge is effectively zero. Neither the half-threshold nor flat-bedded section drains to the base, but maintains a small water elevation that creates a modest water discharge throughout the night before the crevasse refills in the morning.

[89] The morning rise in discharge, followed by the afternoon plateau, evening fall, and nightly minimum discharge translate to the other flow terms. For all simulations, effective pressure decreases during the morning (Figure 10, column 2). Negative effective pressure values develop during daytime and extend to the terminus for all the overdeepened sections. For the flat-bedded case, negative effective pressures extend approximately halfway to the terminus. All of the glacier sections resume positive effective pressures from the upstream feeder crevasse to the terminus during nighttime.

[90] The daily trends in effective pressure yield straightforward cycles in the water velocity (Figure 10, column 3 ). These are highest upstream along the flat portion of the inlet for all sections. Because the water flow generates heat that melts the ice roof, the water depth increases subtly (thick, diurnally modulated contours in Figure 8, column 2), leading to a propagation of higher water velocities downstream over the course of daytime conditions. This daytime propagation is exhibited in the change in spacing of the contours. The gradient in total sediment transport (Figure 10, column 4) shows this offset quite clearly. For all the overdeepened sections, the hydraulic gradients drop to near zero during nighttime. The flat-bedded section has a low but positive gradient driving flow during nighttime.

[91] Deposition of sediments responds to the changing evolution of water depth and hydraulic potential gradient over daytime (Figure 10, column 4). Strongly negative areas, indicated by deeper shades of blue, indicate erosion in the subglacial system. Only the twice-threshold and threshold cases display erosion along the adverse slope (Figures 10a4 and 10b4). The other two sections show an evolution of deposition over the

Table 3. Total Water Throughput and Ice Accretion for 100 Day Simulations

\begin{tabular}{|c|c|c|c|c|}
\hline Longitudinal Section & $\begin{array}{c}\text { Upstream } \\
\text { Recharge Type }\end{array}$ & $\begin{array}{c}\text { Total Water } \\
\text { Throughput }\left(\mathrm{m}^{3} \mathrm{~m}^{-1}\right)\end{array}$ & $\begin{array}{c}\text { Total Accretion } \\
\text { After } 100 \mathrm{~d}\left(\mathrm{~m}^{3} \mathrm{~m}^{-1}\right)\end{array}$ & $\begin{array}{l}\text { Maximum Accretion } \\
\text { Thickness }(\mathrm{m})\end{array}$ \\
\hline Twice threshold & Constant & $2.16 \times 10^{5}$ & 13.0 & 0.12 \\
\hline Threshold & Constant & $2.16 \times 10^{5}$ & 9.8 & 0.12 \\
\hline Half threshold & Constant & $2.16 \times 10^{5}$ & - & 0.04 \\
\hline Twice threshold & Daily & $2.16 \times 10^{5}$ & 12.0 & 0.17 \\
\hline Threshold & Daily & $2.02 \times 10^{5}$ & 2.5 & 0.07 \\
\hline Half threshold & Daily & $1.87 \times 10^{5}$ & - & 0.01 \\
\hline
\end{tabular}


entire length during daytime conditions. The locus of sediment deposition moves downstream as the subglacial water system evolves during daytime. During nighttime, sediment transport shuts down as little water is conveyed through the subglacial hydraulic system for all sections.

[92] Freezing occurs for the three overdeepened sections during morning, evening, and nighttime conditions (Figures $10 \mathrm{a} 5,10 \mathrm{~b} 5$, and $10 \mathrm{c}_{5}$ ). During daytime, water flux through the subglacial system creates a large amount of viscous dissipation that heats the water above freezing. This melts some of the accretion ice for the twice-threshold and threshold cases. For the half-threshold case, all of the ice melts during daytime that accreted during morning and evening conditions. Freezing and accretion are also offset from maximum sediment concentration conditions. Because sediment transport is a maximum during daytime, rather than morning or evening conditions, the sediment concentration in the ice does not track the maximum sediment concentration during daytime. The lower sediment concentrations of morning and evening are recorded in the accretion ice.

\section{Discussion}

[93] In what follows, we relate our model results to other observations and interpretations of the glacier hydraulic system. We relate these results to both alpine glaciers and the major ice sheets.

\subsection{Ice and Sediment Accretion}

[94] Accretion proceeds rapidly where the pressure melting point must adjust as water flows up an adverse slope. The pressure, however, is controlled by drainage conditions and not necessarily by either glacier bed or surface slopes. Thus, our model results are supported by results from Storglaciären, Sweden, where water pressures were observed above the flotation pressures [Hooke, 1991]. Similarly, temperature variations in our modeled subglacial water system tend to be small for the length scales $(\sim 250 \mathrm{~m})$ investigated here, but temperature differences are small, and near instrument precision, where measured in the field [e.g., Tweed et al., 2005]. Neither the warming from frictional dissipation nor the changes in the pressure melting point are large in either model results or in field measurements.

[95] Accreted ice records conditions near the end of an overdeepening. While the accreted ice offers some insight into basal conditions, the sediment stratigraphy appears to record a local signal of erosion along the adverse slope. Local erosion occurs for the threshold and twice-threshold sections with increased sediment transport for the halfthreshold section relative to upstream conditions. Thus, sediment in the ice appears to come from almost immediately below the location of accretion. If the ice is moving, a vertical stratigraphic section will be time-transgressive with higher ice recording water conditions upstream of the terminus. For glaciers that cross multiple overdeepenings in the ablation zone, the relation between exposed basal ice and the location of accretion becomes even more complex.

[96] Inclusion of sediment in the basal ice appears to be governed by a process in the subglacial system that enhances the concentration as ice forms. The model presented here only includes epitaxial ice growth on the ceiling of the water system. It is possible that inclusion of frazil ice processes whereby ice grows as small crystals in the flowing water could allow for the filtering mechanism proposed by Lawson et al. [1998]. As frazil ice flocculates, the conjoined ice crystal network acts as a filter, withdrawing sediment from the flowing water. Such filtering can create concentrations of sediment in the ice greater than in the flowing water. In the present configuration of our model, results suggest a filtering mechanism is appropriate. We have assumed that sediment concentration in the ice varies with sediment concentration in the flowing water. However, a filtering process would make the concentration vary with the rate of ice formation, rather than with the accretion rate or the amount of sediment in the flow. Additional water flow through pore space and other processes that occur during freezing can modify the sediment concentration [Cook et al., 2012]. Ideally, direct observations from the base of a glacier would provide insight. This process merits further investigation so that the basal layers can be used to understand local processes and, in turn, to understand glacial deposits.

[97] Total water throughput is much larger than the amount of ice accreted (see Table 3 ). This means that there must be net melt of the glacier, and Alley et al. [1998] observed that the spatial separation of melt and refreezing allows glaciohydraulic supercooling to occur even though there is no net accretion or positive mass balance to the glacier as a whole. One of the interesting features in our simulations is that the subglacial water system loses its ability to conduct water as sediments are transported through the system. For the diurnally varying simulations, the water depth declines and water does not pass as easily (i.e., lower transmissivity) because the subglacial system clogs with sediment. Thus, because the water system cannot accept the water that is given to it by the surface melt, the system becomes less efficient even though there are ample subglacial water connections.

\subsection{Effects of Pressure Variations from the Diurnal Cycle}

[98] Both ice accretion and sediment transport are affected by the strength of the diurnal cycle. In general, water flow rates that increase dramatically allow increased pressure gradients with enhanced velocities. Higher velocities imply increased viscous dissipation with more heat generated locally in the subglacial water system. Higher velocities can lead also to sediment transport.

[99] We use the effective pressure to understand the distributed nature of the subglacial water system in a simple sense. Whether flow concentrates in channels or is distributed in sheets will be related to the configuration of the water layer relative to sediment and bedrock bumps as well as to how water is collected along flow [Schoof, 2010; Hewitt, 2011]. For channelization, areas of higher effective pressure grow at the expense of those with lower effective pressure [Röthlisberger, 1972]. Low or negative effective pressures tend to correspond to distributed systems, whereas high effective pressures correspond to channelized systems, depending on water flux [Hewitt, 2011; Nye, 1976; Schoof, 2010]. Other, more complicated relations exist between effective pressure and water system behavior [e.g., Creyts and Schoof, 2009; Tsai and Rice, 2010], but we ignore these models because we cannot test them. Even though our model assumes that water is distributed, the effective pressure results give an indication of whether water would distribute over the bed. 
[100] Effective pressure shows end-member behavior for the two types of simulations: constant recharge and diurnal recharge. For the sections with constant recharge, the effective pressure for all but the steepest overdeepenings is positive, suggesting that channelized systems can exist across them. For this boundary condition, only the overdeepening at twice the threshold would have a distributed water system. Here, the water distributes across the bed prior to ascending the adverse slope. Radar data from Matanuska Glacier show loss of bed power in a similar area of the overdeepening. Based on our results, it is possible that water distributes across the base of the overdeepening at Matanuska with water pressures driving flow upward into an englacial hydraulic system. Water in an englacial system would increase radar attenuation in the ice column above the overdeepening and could explain observations at Matanuska Glacier. Similar overpressures were observed at Storglaciären [Hooke, 1991]. Thus, our results suggest that some overdeepenings can have a distributed hydraulic system at the start of the adverse slope, and this could give way to a channelized system as water nears the terminus.

[101] For simulations with diurnally varying discharges, peak water pressures exceed flotation locally during daytime conditions, but pressure drops to sub-flotation during nighttime. Artesian flow has been observed at outlets of glaciers that flow through overdeepenings including Matanuska [Lawson et al., 1998]. This change causes closure to dominate during nighttime when low water pressures do not support the ice overburden pressure. Viscous dissipation then dominates daytime conditions because flux is too great for the water depth and causes melt. This competition between closure and melting means that the hydraulic system is tuned to an intermediate flow rate that is neither the daily maximum nor the nightly minimum. A consequence of the tuning is that steady-state approximations for either sediment transport or ice accretion may not capture system behaviors. Thus, the hydraulic system would switch between a sheet (daytime state) and a channel (nighttime state). The hydraulic system would flood during the day to give additional connections, possibly moving water into off-axis storage during nighttime. The flooding could occur either by hydraulic jacking [e.g., Murray and Clarke, 1995] or fracturing [e.g., Tsai and Rice, 2010] to open the ice-bed interface. With strong diurnal cycles, the water supply would cause a switch from a low-pressure channelized system at night to a distributed, high-pressure system during the day.

[102] For the overdeepened sections, rising discharge in the morning and falling discharge in evening produce freeze-on of ice. For overdeepenings with low slopes, heating from viscous dissipation subsequently melts the ice during the mid-day discharge peak. Results from our model suggest that glaciers with overdeepenings above the threshold for glaciohydraulic supercooling retain some of their ice that is frozen on, but a large percentage melts. For twodimensional systems, it is possible that as ice is frozen on, a lateral feedback can develop whereby flow diverges away from areas of shallow water depth to lower pressure areas. Even though our model cannot capture such behavior, this feedback warrants further investigation.

[103] The simulations with diurnally varying discharge enhance both erosion and sedimentation magnitudes even though the locations of erosion and deposition are nearly the same. For all simulations, erosion occurs only for the most overdeepened sections, and the net effect for the section at half the critical threshold is that there is less deposition along the adverse slope. The velocity peak during the daily maximum in discharge corresponds to a maximum in sediment influx from upstream, so more sediment is available for deposition. Similarly, the higher water velocities correspond to an increase in erosion along steeper adverse slopes where freezing occurs and constricts the hydraulic system. From these features, we expect that glaciers existing in climatic regimes where melt is strongly modulated by daily variations (e.g., glaciers in Southern Alaska), will experience stronger effects of glaciofluvial erosion and sedimentation. Conversely, where climatic regimes are more subdued, erosion and sedimentation will proceed more slowly.

[104] For long glaciers with much ice in the ablation zone, the daytime to nighttime switch in water supply would occur before sediment exits the hydraulic system. Water supply could approach no influx at night, as is explored here; or, alternatively, water could flow out of an englacial aquifer into the subglacial system with modest recharge at night. Drainage of an aquifer would provide conditions similar to the constant recharge conditions. Because erosion and sedimentation would vary spatially with the diurnal cycle, sediment would move down sufficiently long glaciers in a pulsatory fashion.

\subsection{Controls on Deposition and Erosion}

[105] Erosion is modulated by the along-path change in velocity, and this can be approximated by the curvature of the hydraulic potential. For the steady-state, analytic calculations, the curvature is directly dependent on the ice surface and bed slopes. Constant slopes give rise to neither deposition nor erosion, and sediment that enters the subglacial hydraulic system passes without a change in concentration. The configurations of these slopes show that sediment should deposit where the bed turns upward. Alternatively, if the base were to turn downward, erosion of loose sediments would occur.

[106] Numerical simulations show similar features with the curvature of the hydraulic potential governing erosion and deposition. Curvature varies, however, because the water pressure is dynamic. The water system interacts with upstream input and downstream outlet pressure conditions. The result is that a significant amount of deposition occurs where the water system depressurizes along flow. Similarly, where the water pressures stay high, gradients can increase to allow erosion. Notably, the areas where ice accretion occurs steepen pressure gradients and increase velocity locally. Erosion then proceeds in these locations.

[107] Glaciers and ice sheets probably operate in such a way to reduce the hydraulic potential curvature locally, either through sedimentation or erosion. For either very steep bed slopes or strongly varying diurnal discharge, the reduction would be small on a day-to-day basis. Temperate alpine glaciers operate in this fashion with the result being that they are one of the strongest agents of bedrock erosion [e.g., Hallet et al., 1996]. For ice sheets, the steepness of the hydraulic potential gradient is largely controlled by the flow of ice. For ice that is deforming internally such that the shallow ice approximation is valid [Cuffey and Paterson, 2010], sediment transport will be closely coupled to the curvature of the ice surface and thickness. For streaming ice where water flows 
beneath low-gradient ice, such as the Siple Coast in West Antarctica [e.g., Alley and Bindschadler, 2001], the effective pressure gradients are on the order of the ice surface gradients [Kamb, 2001]. This coupling with the effective pressure means that sediment transport is possibly determined by how water flows [e.g., Fricker and Scambos, 2009] rather than being largely controlled by either ice sheet surface curvature or ice thickness.

[108] In one of the few studies that used the form of the past ice sheet and subglacial hydrology, Shreve [1985] examined the role of glaciohydraulic supercooling on sediment transport for the Katahdin esker system of Maine, USA, deposited by the Laurentide Ice Sheet. He noted that the structure, texture, and form of the sedimentary deposits change where water moves from melting conditions to areas where glaciohydraulic supercooling occurs. Areas where the channel melts have sharp-crested eskers with poorly sorted textures that exhibited poor or absent bedding. He also suggested that areas where supercooling occurred had broad-crested eskers that were well-sorted and well-bedded. Shreve [1985] thought of the sediment in the sharp-crested eskers as being proximally sourced from melting of the overlying ice whereas the broad-crested eskers as having a distal source because of the bedding and roundedness of the clasts.

[109] The Katahdin esker system contains more complexity than our model captures. Two-dimensional water paths and sorting of sediments are chief among these, and we cannot make strong statements about the observations discussed by Shreve [1985]. Nevertheless, inferences lie chiefly on the sediment transport going down as water ascends an adverse bed slope. As we have shown, this assumption requires careful application. Our results show the opposite behavior where water can increase velocity to move more sediment. Furthermore, much sediment in eskers must be distally sourced, and water flux could be rejuvenated as surface melt makes it to the bed through moulins or crevasses in the ablation zone. Observations from Greenland show similar rejuvenation [Palmer et al., 2011], and the southern Laurentide Ice Sheet likely behaved this way. The sediment bedding could then be a function of the water shear stress or rate of deposition that would be coupled to the effective pressure and drainage. One aspect of the eskers that Shreve [1985] did not comment on is that they terminate to form gaps before reemerging along path downstream. These gaps could be caused by local erosion where freezing occurs similar to what we observe in our model. The possibility that basal ice accretion from supercooling affects the character of eskers is novel and merits further attention.

[110] For long-term glaciofluvial erosion to occur, the hydraulic gradient must steepen along flow. Conversely, where deposition occurs over the long term, the hydraulic gradient should lower along flow. Stabilizing feedbacks via sediment armoring the bed to prevent erosion thus require lessening of the hydraulic gradient. Our results show that there are regimes where erosion occurs along adverse slopes that are directly related to glaciohydraulic supercooling. In these results, the flow velocity increases because the water depth decreases where ice freezes on to the base of the glacier. Glaciohydraulic supercooling, therefore, does not necessarily impart a stabilizing feedback to subglacial hydrology. Even though our model does not capture lateral divergence of water along the bed, any freeze-on over long time periods would have a similar effect. It is possible, however, that the transmissivity drop from freezeon would cause all water flow to be englacial. Observations suggest that englacial transport can be significant through glaciers with overdeepenings [Fountain et al., 2005; Hooke, 1991; Hooke and Pohjola, 1994].

[111] If upward, englacial transmissivity is low and water is confined to the bed, there may be an equilibrium between erosion and deposition at some intermediate bed to surface slope ratio that is governed by sediment transport and its relation to the water flow variables. The long-term trends from both sets of simulations show erosion along steep overdeepenings and deposition along shallow overdeepenings. Thus, very steep overdeepenings tend to change slope ratios to those that preclude freezing from glaciohydraulic supercooling, but shallow bed slopes tend to steepen a small amount. There is likely an intermediate state dependent on water flux and glacier geometry that can be attained over very long time scales.

\section{Conclusions}

[112] We developed a diagnostic, along-path, water flow model to investigate the relation between glaciohydraulic supercooling and sediment transport. Modifications to existing theory included direct coupling of the Exner equation as well as tracking both suspended sediment load and bed load. This model is the first coupled model of subglacial thermodynamics and sediment transport that can be used to infer dynamics of water flow through overdeepenings. Our continuum formulation is general enough to allow other sediment transport rules to be substituted and tested. These additions allow us to understand how water flow changes as sediment is eroded or deposited. Our untuned model results show basal ice accretion that is roughly equivalent in magnitude to field sites.

[113] Because we assumed that sediment concentration in this accreted ice varies directly with sediment concentration in the subglacial water system, results show concentrations that are far too low relative to field sites. A better assumption likely includes a process that is dependent on the rate of ice formation in the subglacial water system.

[114] The diurnal cycle has a large effect on subglacial sediment erosion and deposition. Very strong diurnal cycles lead to high pressures during daytime and low pressures at nighttime. The result is that subglacial water depth tunes neither to daytime nor nighttime conditions exactly but some combination of the two. This allows water depth to be low relative to daily maxima in discharge, increasing water pressures upstream, and steepening water flow gradients. Such behaviors likely lead to a wealth of sediment transport phenomena, and influence of these cycles on field sites merits further investigation.

[115] Once an overdeepening is established, its evolution is governed by the amount of material deposited or removed from it. This will depend on the amount of water that flows along the ice-bed interface, the amount of sediment it transports, and how the water velocity evolves across the overdeepening. It appears that overdeepenings allow strong sediment deposition by forcing water to flow upward through an englacial water system. Alternatively, if water 


\section{CREYTS ET AL.: SEDIMENT REDISTRIBUTION AND GLACIOHYDRAULIC SUPERCOOLING}

does flow at the bed, very steep adverse slopes appear to drive the system toward shallower values through downstream erosion. Meanwhile, shallow slopes tend to enhance sedimentation and steepen. These results arise from sediment transport theory, and both further theoretical and field studies are warranted.

\section{Notation}

[116] Conventions: For any variable $X, X_{\mathrm{i}}$ refers to the overlying ice, $X_{\mathrm{w}}$ refers to the subglacial water system, $X_{\mathrm{b}}$ refers to the subglacial bed, and $X_{\mathrm{s}}$ refers to subglacial sediment. The combination of these are $X_{\mathrm{sw}}$, a reference to sediment in the subglacial water system, and $X_{\mathrm{si}}$, a reference to sediment in the overlying ice. Variables pertaining to the upstream feeder crevasse commonly take a subscript $X_{c}$. The two sediment classes, bed load and suspended load, are denoted $X_{\mathrm{y}: \text { bed }}$ and $X_{\mathrm{y}: \text { sus }}$, respectively, with y being another subscript, usually ${ }_{\mathrm{w}}, X_{\mathrm{b}}$, , or $_{\mathrm{s}}$. In general, summation of bed and suspended load components gives $X_{\mathrm{y}}$ : bed $+X_{\mathrm{y}}$ : sus $=X_{\mathrm{y}}$. The only common superscript notation is use of the tilde where $\widetilde{X}$ refers to a width-averaged quantity.

$A_{c} \quad$ Crevasse cross-sectional area.

$c_{\mathrm{W}} \quad$ Water specific heat at constant pressure.

$D$ Representative grain diameter.

$f_{d} \quad$ Darcy-Weisbach friction factor averaged over the hydraulic perimeter.

$f_{\mathrm{b}}{ }^{\prime} \quad$ Darcy-Weisbach grain friction factor for the bed.

$f_{\mathrm{b}}{ }^{\prime \prime} \quad$ Darcy-Weisbach form friction factor for the bed.

$f_{\mathrm{i}}$ Darcy-Weisbach friction factor for the ice.

$g$ Gravitational acceleration.

$H \quad$ Water depth (= sheet thickness).

$K$ Thermal conductivity.

$L \quad$ Ice latent heat.

$L_{\mathrm{s}} \quad$ Sediment adaptation length.

$m$ Melt rate.

$\widetilde{m} \quad$ Melt rate per unit melting perimeter.

$n_{\mathrm{i}} \quad$ Ice porosity.

$n_{\mathrm{b}} \quad$ Bed porosity.

$p_{c} \quad$ Hydrostatic pressure in the upstream feeder crevasse.

$p_{e} \quad$ Effective pressure.

$p_{\mathrm{i}} \quad$ Ice overburden pressure.

$p_{\mathrm{w}} \quad$ Subglacial water pressure.

$Q_{\text {w }} \quad$ Width-averaged subglacial water flux.

$Q_{\text {melt }}$ Water discharge into the upstream crevasse.

$Q_{\text {ref }}$ Reference water discharge into the upstream crevasse.

$q_{\text {sw }}$ Sediment flux.

$q_{\text {sw,e }} \quad$ Equilibrium sediment flux.

$q_{\text {sw }: \text { bed }}$ Bed load sediment flux.

$q_{\text {sw } \text { : sus }}$ Suspended load sediment flux.

$\mathcal{R}$ Glacier surface to bed slope ratio.

$\mathcal{R}_{c r}$ Critical surface to bed slope ratio necessary for supercooling.

$S$ Subglacial water cross-sectional area.

$s \quad$ Along-flow coordinate.

$T_{c} \quad$ Upstream crevasse water temperature.

$T_{m} \quad$ Ice melting temperature.
$T_{\mathrm{w}} \quad$ Water temperature.

$t$ Time.

$u$ Water velocity.

$W \quad$ Water flow width (taken as unit width).

$x$ Longitudinal coordinate.

$Z_{c} \quad$ Upstream crevasse water depth.

$Z_{\mathrm{i}} \quad$ Ice thickness.

$Z_{\text {iw }}$ Accreted basal ice thickness.

$z_{\mathrm{i}} \quad$ Ace surface elevation.

$z_{\mathrm{b}} \quad$ Bed elevation.

$z_{\mathrm{w}} \quad$ Subglacial ice-water interface elevation.

$n$ Vertical coordinate.

$\tan \alpha_{i} \quad$ Glacier surface slope.

$\tan \alpha_{\mathrm{w}} \quad$ Water system slope (= bed slope).

$\beta$ Pressure melting parameter.

$\gamma$ Subglacial compressibility.

$\delta_{\text {bed }} \quad$ Bed load layer thickness.

$\lambda_{\mathrm{sw}}$ Total sediment concentration in basal water system, $\lambda_{\text {sw }}=\lambda_{\text {sw : bed }}+\lambda_{\text {sw : sus }}$.

$\lambda_{\text {sw } \text { : bed }}$ Bed load concentration in basal water system.

$\lambda_{\text {sw:sus }}$ Suspended load concentration in basal water system.

$\lambda_{\mathrm{si}}$ Total sediment concentration in accreted basal ice, $\lambda_{\mathrm{si}}=\lambda_{\mathrm{si}: \text { bed }}+\lambda_{\mathrm{si}: \text { sus }}$.

$\lambda_{\text {si : bed }}$ Bed load concentration in ice.

$\lambda_{\text {si : sus }}$ Suspended load concentration in ice.

$\rho_{\mathrm{i}} \quad$ Ice mass density.

$\rho_{\mathrm{w}} \quad$ Water mass density.

$\rho_{\mathrm{s}} \quad$ Dry sediment mass density.

$\phi \quad$ Hydraulic potential driving flow.

$\widetilde{\Psi}_{\mathrm{b}} \quad$ Sediment supply from bed to water per unit width.

$\widetilde{\Psi}_{\mathrm{i}} \quad$ Sediment supply from ice to water per unit melting perimeter.

$\tau_{0} \quad$ Shear stress along the hydraulic perimeter.

$\tau_{\mathrm{i}}$ Shear stress along ice-bound portion of the hydraulic perimeter.

$\tau_{\mathrm{b}}{ }^{\prime} \quad$ Shear stress on the mobile grains along the bed.

$\tau_{\mathrm{b}}{ }^{\prime \prime} \quad$ Shear stress on the bedforms.

[117] Acknowledgments. We thank Richard Alley, Dan Lawson, and Christian Schoof for helpful discussions. We express gratitude to Simon Cook and two anonymous referees for help improving an earlier version of this manuscript. This work was funded by the US NSF Office of Polar Programs, Canada's Natural Sciences and Engineering Research Council, and the University of British Columbia.

\section{References}

Abbott, J. E., and J. R. D. Francis (1977), Saltation and suspension trajectories of solid grains in a water stream, Proc. Roy. Soc. Lond. A Mat., 284(1321), 225-254.

Alley, R. B., and R. A. Bindschadler (2001), The West Antarctic Ice Sheet and sea-level rise, in The West Antarctic Ice Sheet: Behavior and Environment, Antarctic Research Series, vol. 77, edited by R. B. Alley and R. A. Bindschadler, pp. 1-11, American Geophysical Union, Washington, DC.

Alley, R. B., D. E. Lawson, E. B. Evenson, J. C. Strasser, and G. J. Larson (1998), Glaciohydraulic supercooling: A freeze-on mechanism to create stratified, debris-rich basal ice. II: Theory, J. Glaciol., 44(148), 563-569.

Alley, R. B., D. E. Lawson, G. J. Larson, E. B. Evenson, and G. S. Baker (2003a), Stabilizing feedbacks in glacier-bed erosion, Nature, 424, 758-760.

Alley, R. B., D. E. Lawson, E. B. Evenson, and G. J. Larson (2003b), Sediment, glaciohydraulic supercooling, and fast glacier flow, Ann. Glaciol., 36, 135-141. Armanini, A., and G. di Silvio (1988), A one-dimensional model for the transport of a sediment mixture in non-equilibrium conditions, J. Hydraul. Res., 26(3), 275-292.

Bagnold, R. A. (1973), The nature of saltation and of 'bed load' transport in water, Proc. Roy. Soc. Lond. A Mat., 332, 473-504.

Benn, D. I., and D. J. A. Evans (1998), Glaciers and Glaciation, Arnold, London. 


\section{CREYTS ET AL.: SEDIMENT REDISTRIBUTION AND GLACIOHYDRAULIC SUPERCOOLING}

Carstens, T. (1966), Experiments with supercooling and ice formation in flowing water, Geofys. Publ., 26(9), 1-18.

Church, M., M. A. Hassan, and J. F. Wolcott (1998), Stabilizing selforganized structures in gravel-bed stream channels: Field and experimental observations, Water Resour. Res., 34(11), 3169-3179.

Clarke, G. K. C. (2003), Hydraulics of subglacial outburst floods: New insights from the Spring-Hutter formulation, J. Glaciol., 49(165), 299-313.

Cook, S., and D. Swift (2012), Subglacial basins: Their origin and importance in glacial systems and landscapes, Earth Sci. Rev., 115(4), 332-372, doi:10.1016/j.earscirev.2012.09.009.

Cook, S., Z. Robinson, I. Fairchild, P. Knight, R. Waller, and I. Boomer (2010), The role of glaciohydraulic supercooling in the formation of stratified facies basal ice: Svínafellsjökull and Skaftafellsjökull, southeast Iceland, Boreas, 39(1), 24-38, doi:10.1111/j.1502-3885.2009.00112.x.

Cook, S. J., P. G. Knight, and R. I. Waller (2006), Glaciohydraulic supercooling: the process and its significance, Prog. Phys. Geog., 30(5), 577-588, doi:10.1177/0309133306071141.

Cook, S. J., P. G. Knight, R. I. Waller, Z. P. Robinson, and W. G. Adam (2007), The geography of basal ice and its relationship to glaciohydraulic supercooling: Svínafellsjökull, southeast Iceland, Quat. Sci. Rev., 26(19-21), 2309-2315, doi:10.1016/j.quascirev.2007.07.010.

Cook, S. J., P. G. Knight, D. A. Knight, and R. I. Waller (2012), Laboratory observations of sediment entrainment by freezing supercooled water, Geogr. Ann. A, 94(19-21), 351-362, doi:10.1111/j.1468-0459.2011.00445.x.

Creyts, T. T., and G. K. C. Clarke (2010), Hydraulics of subglacial supercooling: Theory and simulations for clear water flows, J. Geophys. Res., 115, F03021, doi:10.1029/2009JF001417

Creyts, T. T., and C. G. Schoof (2009), Drainage through subglacial water sheets, J. Geophys. Res., 114, F04008, doi:10.1029/2008JF001215.

Cuffey, K. M., and W. S. B. Paterson (2010), The Physics of Glaciers, 4th ed., 693 pp., Butterworth-Heinemann/Elsevier, Burlington, MA.

Daly, S. F. (1984), Frazil ice dynamics, Tech. Rep. 84-1, U.S. Army CRREL, Hanover, NH.

Einstein, H. A. (1968), Deposition of suspended particles in a gravel bed, J. Hydraul. Div. Am. Soc. Civ. Eng., 95(5), 1197-1205.

Fountain, A. G., R. W. Jacobel, R. Schlichting, and P. Jansson (2005), Fractures as the main pathways of water flow in temperate glaciers, Nature, 433(7026), 618-621, doi:10.1002/esp.1038.

Fricker, H. A., and T. Scambos (2009), Connected subglacial lake activity on lower Mercer and Whillans Ice Streams, West Antarctica, 2003-2008, J. Glaciol., 55(190), 303-315.

Garcia, M., and G. Parker (1991), Entrainment of bed sediment into suspension, J. Hydraul. Eng., 117(4), 414-435.

Garcia, M. H. (2008), Sediment transport and morphodynamics, in Sedimentation Engineering Processes, Measurements, Modeling, and Practice, ASCE Manuals and Reports on Engineering Practice, vol. 110, pp. 21-163, American Society of Civil Engineers, Reston, VA.

Gomez, B., and M. Church (1989), An assessment of bed load sediment transport formulae for gravel bed rivers, Water Resour. Res., 25(6), 1161-1186.

Hallet, B. (1979), A theoretical model of glacial abrasion, J. Glaciol., 23, 39-50. Hallet, B. (1996), Glacial quarrying: A simple theoretical model, Ann. Glaciol., $22,1-8$.

Hallet, B., L. Hunter, and J. Bogen (1996), Rates of erosion and sediment evacuation by glaciers: A review of field data and their implications, Global Planet. Change, 12, 213-225.

Hammar, L., and H. T. Shen (1995), Frazil evolution in channels, J. Hydraul. Res., 33(3), 291-306.

Henderson, F. M. (1966), Open Channel Flow, MacMillan, New York.

Hewitt, I. J. (2011), Modelling distributed and channelized subglacial drainage, J. Glaciol., 57(202), 302-314.

Hildes, D. H. D. (2001), Modelling subglacial erosion and englacial sediment transport of the North American Ice Sheets, Ph.D. thesis, University of British Columbia, Vancouver, BC, Canada.

Hildes, D. H. D., G. K. C. Clarke, G. E. Flowers, and S. J. Marshall (2004), Subglacial erosion and englacial sediment transport modelled for North American ice sheets, Quat. Sci. Rev., 23(3-4), 409-430.

Hooke, R. L. (1991), Positive feedbacks associated with erosion of glacial cirques and overdeepenings, Geol. Soc. Am. Bull., 103(8), 1104-1108.

Hooke, R. L., and N. R. Iverson (1995), Grain-size distribution in deforming subglacial tills: Role of grain fracture, Geology, 23(1), 57-60.

Hooke, R. L., and V. Pohjola (1994), Hydrology of a segment of a glacier situated in an overdeepening, Storglaciären, Sweden, J. Glaciol, 40(134), $140-148$.

Hubbard, B., S. Cook, and H. Coulson (2009), Basal ice facies: A review and unifying approach, Quat. Sci. Rev., 28, 1956-1969, doi:10.1016/j. quascirev.2009.03.005.
Iken, A., and R. A. Bindschadler (1986), Combined measurements of subglacial water pressure and surface velocity of Findelengletscher, Switzerland: Conclusions about drainage system and sliding mechanism, J. Glaciol., 32(110), 101-119.

Iverson, N. R., and D. J. Semmens (1995), Intrusion of ice into porous media by regelation: A mechanism of sediment entrainment by glaciers, J. Geophys. Res., 100(B4), 10,219-10,230.

Kamb, B. (2001), Basal zone of the West Antarctic ice streams and its role in lubrication of their rapid motion, in The West Antarctic Ice Sheet: Behavior and Environment, Antarctic Research Series, vol. 77, edited by R. B. Alley and R. A. Bindschadler, pp. 157-199, American Geophysical Union, Washington, DC.

Khatwa, A., J. K. Hart, and A. J. Payne (1999), Grain textural analysis across a range of glacial facies, Ann. Glaciol., 28, 111-117.

Lawson, D. E. (1979), Sedimentological analysis of the western terminus region of the Matanuska Glacier, Alaska, Tech. Rep. 79-9, U.S. Army CRREL, Hanover, NH.

Lawson, D. E. (1993), Glaciohydrologic and glaciohydraulic effects on runoff and sediment yield in glacierized basins, Tech. Rep. 93-2, U.S. Army CRREL, Hanover, NH.

Lawson, D. E., J. C. Strasser, E. B. Evenson, R. B. Alley, G. J. Larson, and S. A. Arcone (1998), Glaciohydraulic supercooling: A freeze-on mechanism to create stratified, debris-rich basal ice. I: Field evidence, J. Glaciol., 44(148), 547-562.

Lee, H. Y., and I. S. Hsu (1994), Investigation of saltating particle motions, J. Hydraul. Eng., 120(7), 831-845.

Murray, T., and G. K. C. Clarke (1995), Black-box modeling of the subglacial water system, J. Geophys. Res., 100(B7), 10,231-10,245.

Nienow, P., M. Sharp, and I. Willis (1998), Seasonal changes in the morphology of the subglacial drainage system, Haut Glacier D'Arolla, Switzerland, Earth Surf. Processes Landforms, 23(9), 825-843.

Nye, J. F. (1953), The flow law of ice from measurements in glacier tunnels, laboratory experiments and the Jungfraufirn, Proc. Roy. Soc. Lond. A Mat., 219, 477-489.

Nye, J. F. (1976), Water flow in glaciers: Jökulhlaups, tunnels, and veins, J. Glaciol., 17(76), 181-207.

Palmer, S., A. Shepherd, P. Nienow, and I. Joughin (2011), Seasonal speedup of the Greenland Ice Sheet linked to the routing of surface water, Earth Planet. Sci. Lett., 302(3-4), 423-428, doi:10.1016/j. eps1.2010.12.037.

Paterson, W. S. B. (1994), The Physics of Glaciers, 3rd ed., Pergamon, Tarrytown, NY.

Pearce, J. T., F. J. Pazzaglia, E. B. Evenson, D. E. Lawson, R. B. Alley, D. Germanoski, and J. D. Denner (2003), Bedload component of glacially discharged sediment: insights from the Matanuska Glacier, Alaska, Geology, 31(1), 7-10.

Phillips, B. C., and A. J. Sutherland (1989), Spatial lag effects in bed load sediment transport, J. Hydraul. Res., 27(1), 115-203.

Rempel, A. W. (2008), A theory for ice-till interaction and sediment entrainment beneath glaciers, J. Geophys. Res., 113(F1), F01013, doi:10.1029/2007JF000870.

Richards, K., M. Sharp, N. Arnold, A. Gurnell, M. Clark, M. Tranter, P. Nienow G. Brown, I. Willis, and W. Lawson (1996), An integrated approach to modelling hydrology and water quality in glacierized catchments, Hydrol. Processes, 10(4), 479-508.

Roberts, M. J., F. S. Tweed, A. J. Russell, Ó. Knudsen, D. E. Lawson, G. J. Larson, E. B. Evenson, and H. Björnsson (2002), Glaciohydraulic supercooling in Iceland, Geology, 30(5), 439-442.

Röthlisberger, H. (1972), Water pressure in intra- and subglacial channels, J. Glaciol., 11(62), 177-203.

Röthlisberger, H., and H. Lang (1987), Glacial hydrology, in Glacio-Fluvial Sediment Transfer: An Alpine Perspective, edited by A. M. Gurnell and M. J. Clark, pp. 207-284, John Wiley and Sons, New York.

Schoof, C. (2010), Ice-sheet acceleration driven by melt supply variability, Nature, 468, 803-806, doi:10.1038/nature09618.

Shreve, R. L. (1972), Movement of water in glaciers, J. Glaciol., 11(62), 205-214.

Shreve, R. L. (1985), Esker characteristics in terms of glacier physics, Katahdin esker system, Maine, Geol. Soc. Am. Bull., 96, 639-646.

Spring, U., and K. Hutter (1981), Numerical studies of jökulhlaups, Cold Reg. Sci. Technol., 4(3), 227-244.

Spring, U., and K. Hutter (1982), Conduit flow of a fluid through its solid phase and its application to intraglacial channel flow, Int. J. Eng. Sci., 20(2), 327-363.

Staniforth, A., and J. Côté (1991), Semi-Lagrangian integration schemes for atmospheric models-A review, Mon. Weather Rev., 119(9), 2206-2223.

Strasser, J. C., D. E. Lawson, G. J. Larson, E. B. Evenson, and R. B. Alley (1996), Preliminary results of tritium analyses in basal ice, Matanuska 


\section{CREYTS ET AL.: SEDIMENT REDISTRIBUTION AND GLACIOHYDRAULIC SUPERCOOLING}

Glacier, Alaska, U.S.A.: Evidence for subglacial ice accretion, Ann. Glaciol., $22,126-133$.

Sugden, D. E., and B. S. John (1976), Glaciers and Landscape, pp. 151-258, Edward Arnold, London.

Tsai, V. C., and J. R. Rice (2010), A model for turbulent hydraulic fracture and application to crack propagation at glacier beds, J. Geophys. Res., 115, F03007, doi:10.1029/2009JF001474.

Tulaczyk, S., R. P. Scherer, and C. D. Clark (2001), A ploughing model for the origin of weak tills beneath ice streams: A qualitative treatment, Quat. Int. $86,59-70$.

Tweed, F. S., M. J. Roberts, and A. J. Russell (2005), Hydrologic monitoring of supercooled meltwater from Icelandic glaciers, Quat. Sci. Rev., 24, 2308-2318, doi:10.1016/j.quascirev.2004.11.020.

van Rijn, L. C. (1984a), Sediment transport. Part I: Bed load transport, J. Hydraul. Eng., 110(10), 1431-1456. van Rijn, L. C. (1984b), Sediment transport. Part II: Suspended load transport, J. Hydraul. Eng., 110(11), 1613-1641.

Walder, J. S., and A. Fowler (1994), Channelized subglacial drainage over a deformable bed, J. Glaciol., 40(134), 3-15.

Weertman, J. (1957), On the sliding of glaciers, J. Glaciol., 3(21), 33-38.

Willis, I. C., K. S. Richards, and M. J. Sharp (1996), Links between proglacial stream suspended sediment dynamics, glacier hydrology and glacier motion at Midtdalsbreen, Norway, Hydrol. Processes, 10(4), 629-648.

Wu, W., D. Vieira, and S. S. Y. Wang (2004), One-dimensional numerical model for nonuniform sediment transport under unsteady flows in channel networks, J. Hydraul. Eng., 130(9), 914-923, doi:10.1061/(ASCE)07339429(2004)130:9(914).

Yalin, M. S. (1972), Mechanics of Sediment Transport, pp. 290, Pergamon, New York. 